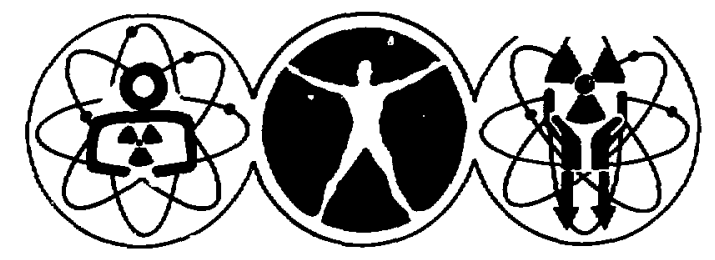

Conf $790304--$

\title{
GEOLOGICAL DISPOSAL OF NUCLEAR WASTE \\ MOTIGE
}

PORTIOHS OF THIS REPOAT ARE ILLECABLE it has been reproduced frem the best

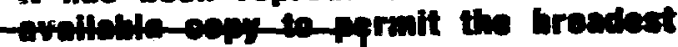
possibula avellewilty.

\section{9th ANNUAL SYMPOSIUM}

\author{
SESSION I \\ INTRODUCTORY SESSION \\ SESSION II \\ SEABED DISPOSAL \\ SESSION III \\ DISPOSAL IN ROCK \\ SESSION IV \\ DISPOSAL IN SALT
}

\author{
MARCH 15 and 16, 1979 \\ PHYSICS LECTURE HALL UNIVERSITY OF NEW MEXICO \\ ALBUQUeRQUE, NEW MEXICO
}

\section{JOINTLY SPONSORED BY}

NEW MEXICO SECTION

AMERICAN SOCIETY OF

MECHANICAL ENGINEERS
COLLEGE OF ENGINEERING UNIVERSITY OF NEW MEXICO 


\section{TABLE OF CONTENTS}

GEOLOGICAL DISPOS

NUCLEAR WASTE

Everet $\mathrm{H}$. Beckner

Sandia Laboratories

CHARACTERIZATION OF

NUCLEAR WASTE

A. M. Platt

Battelle Pacific Northwest

Laboratory

RADIOACTIVE WASTE

TREATMENT TECHNOLOGY

R. D. Walton, Jr.

U. S. Department of Energy

TRANSPORTATION OF

NUCLEAR WASTE

E. C. Hardin, Jr.

U. S. Department of Energy

SITE SELECTION

19

Charles D. Holister

Woods Hole Oceanographic

Institution

ION TRANSPORT

G. R. Heath

Oregon State University

NEAR FIELD INTERACTIONS

James L. Krumhans|

Dave F. McVey

Sandia Laboratories

PHYSICAL AND BIOLOGICAL

TRANSPORT

Melvin G. Marietta

Sandia Laboratories

IMPLACEMENT AND

SEDIMENTARY RESPONSE

Paul R. Dawson:

Sandia Laboratories

STATUS OF EVALUATION

OF TUFFS IN SOUTHERN

NEVADA FOR WASTE

DISPOSAL

Allen R. Lappin

Sandia Laboratories

Bruce M. Crowe

Los Alamos Scientific

Laboratories

GEOLOGICAL DISPOSAL

INVESTIGATIONS IN

GRANITE AT THE NEVADA

TEST SITE

Lynden Ballou

Lawrence Livermore

Laboratories 


\section{TABLE OF CONTENTS(Continued)}

WASTE DISPOSAL IN

RESULTS FOR STRIPA

SWEDEN

Neville G. W. Cook

University of

California at Berkeley

John E. Gale

University of Waterloo

Paul A. Witherspoon

Lawrence Berkeley

Laboratories

EVALUATION OF BASALT

FLOWS AS A WASTE

ISOLATION MEDIA

Paul DeJue

Rockwell Richland

THERMAL AND

MECHANICAL

RESPONSES OF THE

CONGASAUGA AND ELEANA

FORMATIONS

James L. Krumhans'

Lynn D. Tyler

Sandia Laboratories

GENERIC ASPECTS OF

SALT REPOSITORIES

Bob Laughon

Battelle Memorial

Institute

FACILITY DESIGN

Leo W. Scully Sandia Laboratories

SITE EVALUATION FOR

WIPP

Leslie R. Hill

Sandia Laboratories

TECHNICAL ISSUES

FOR WIPP

Thomas $\mathrm{O}$. Hunter

Sandia Laboratories

SAFETY ANALYSIS

Joseph P. Brannen

Sandia Laboratories

*This paper was not received in time to be included in the published proceedings. 
GEOLOGIC DISPOSAL OF NUCLEAR WASTE

E. H. Beckner

Sandia Laboratories

This paper is devoted to summarizing the many issues which now can be identified that impact disposal of nuclear waste in geologic repositories, particularly as they are effecting the WIPP project. They range from possible actions of state and national legislatures to details of geologic investigations and risk analyses. Several which are particularly important at this time, generally because they may delay progress, are:

1. Presidential decisions regarding commercial waste forms (spent fuel versus reprocessing)

2. Uncertain State and Federal legislative actions regarding rights of concurrence or veto powers

3. Uncertain Congressional actions regarding licensing of facilities, supporting or contrary to DOE plans

4. Technical impacts of chemical and physical characteristics of waste forms, and the necessity at present to deal with several options

5. Uncertain technical positions of prestigious organizations on acceptable criteria for geologic repositories

6. Uncertain actions of state and Federal bodies regarding land access and/or acquisition

7. Legal and/or political actions of environmental or citizens groups to delay or destroy nuclear programs

8. Issues associated with transportation of wastes 
9. Uncertainties regarding pending EPA requirements for waste repositories

10. Uncertain delays and associated cost escalations resulting from NEPA procedures

11. Uncertainties as sociated with "first-of-a-kind" NRC licensing procedures

12. Difficulties in controlling project costs in light of the above, and inevitable associated public and political criticism if such projects are not controlled in cost and schedule

Several technical issues for the WIPP repository will also be discussed. At this time the principal issues relate primarily to: (1) natural dissolutioning phenomena, (2) repository response to heat-producing wastes, and (3) long-term integrity of waste containers in salt repositories. 


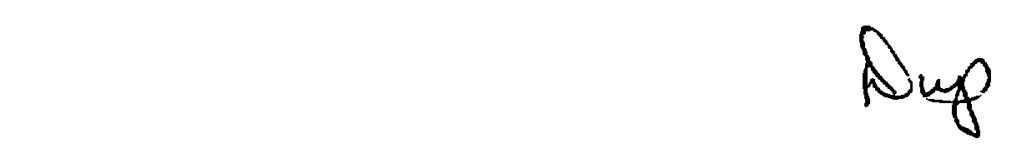

CHARACTERIZATION OF NUCLEAR WASTE

Allison M. Platt

Pacific Northwest Laboratory

Richland, Washington 99352

Nuclear waste has recently $(1)$ been defined in part by the US

Environmental Protection Agency as those materials that "are humanproduced by nuclear fission or activation---". This def,nition encompasses all waste materials from the commercial and defense nuclear fuel cycles and those waste radioisotopes from institutions.

For the purpose of this meeting and this paper, only those nuclear wastes which are logical candidates for deep geological disposal will be considered. Thus institutional, mining and milling, conversion, uranium fuel fabrication and non-TRU wastes from the nuclear fuel cycle will be excluded.

The broad categories of wastes are shown in Table?.

\author{
Table 1 \\ Nuclear Wástes \\ Commercial Waste \\ Spent Fue1 \\ Reprocessing \\ Existing \\ Future \\ Defense Waste \\ Existing \\ Future
}


As most of you know, on April 7, 1977, President Carter, as a result of concerns about proliferation, indefinitely deferred commercial reprocessing and recycling of plutgpjum produced by the US nuclear program. Subsequent documentation ${ }^{(2)}$ by DOE stated that the current Federal plan is to store fuel elemerits retrievably, pending future decisions concerning recovery of their residual fuel vaiues.

A major international effort, the International Fuel Cycle Evaluation, and a major US effort, the Nonprcliferarion A1ternative Systems Assessment Program, were launched to evaluate fuel cycles with and without reprocessing. The major findings of these studies will be available this year.

As of December 31,1978 , some $1.3 \times 10^{15} \mathrm{kWh}$ of electricity had been produced by nuclear reactors in the United States. Opefafing reactors numbered 72 and an additional 161 reactors had been $(3)$ announced, ordered or were under construction. Best estimates are foi some 380,000 MW of nuclear electrical generating capacity in the year 2000.

If this growth projection is valid and, depending on a variety of other factors such as load factor, integrated exposure of the fuel, and useful 1 ifetime of the reactors, it is expected that the 5250 (metric) tonnes of spent fuel discharged through the end of 1978 would increase to about 100,000 tonnes by the end of the year 2000 .

If spent fuel is the selected waste furm, we will be dealing with discharged PWR and BWR fuel with the characteristics shown in Table 2.

The exact treatment and packaging of spent fuel for US geologic disposal has not been specified. Most concepts involve a rather simple secondary container for one PWR element or three BWR elements with an inert solid filler such as sand or aluminum powder and/or helium fill. With a reactor mix of two PWR's and one BWR, about 200,000 packages of spent fuel would be generated through the year 2000 .

Table 2

Spent Fuel

$\begin{array}{lcc} & \text { PWR } & \text { BWR } \\ \text { Length, m } & 4.0 & 4.5 \\ \text { Cross Section, cm } & 21.4 \times 21.4 & 13.9 \times 13.9 \\ \text { Fuel Array } & 17 \times 17 & 8 \times 8 \\ \text { HM Content, kg } & 467.4 & 188.7 \\ \text { Zy, kg } & 129.7 & 56.7 \\ \text { Total Weight, } \mathrm{kg} & 668.6 & 279.0\end{array}$




\section{REPROCESSING MODE}

If a decision is taken to initiate reprocessing in the US, the waste picture would change substantially. Spent fuel would no longer be a waste, but a sizable fraction of tlie wastes produced by the additional fuel cycle operations for reprocessing and mixed oxide (uranium and plitonium) fuel fabrication would be destined for geologic disposal. The typical quantities of waste expected from a GWe-yr of nuclear energy production are shown in Table 3.

Based on the previously stated nuclear power growth, some 2750 GWe years would be produced through the year 2000 .

High-level waste would probably be converted to a product consisting of borosilicate glass in steel containers up to $0.3 \mathrm{~m}$ diam by $3 \mathrm{~m}$ long. The other wastes would probably be placed in 200-liter drums with or without an external concrete shield, depending on the gamma activity.

It is difficuli to estimate how soon reprocessed waste from a commercial operation could be available to initiate geologic disposal experiments and operations. Simple assumptions such as two years to the decision and a dozen years to design, construct and license a reprocessing plant (or waste solidification facilities for AGNS) indicate the mid-nineties before significant quantities of waste from reprocessing (particularly nigh-level) would be available.

\section{Table 3}

\section{LWR Nuclear Wastes}

Vitrified high $\overline{3}$ level waste Volume, $\mathrm{m}^{3} \quad 2.8$

Contained $\mathrm{Pu}, \mathrm{kg} \quad 3.4$

Radioactivity, $\mathrm{MCi}$

Intermediate-level waste

Volume (in concrete), $\mathrm{m}^{3}$

Contained $\mathrm{Pu}, \mathrm{kg}$

Radioactivity, MCi 0.07

Hulls and spacers

Volume (compacted), $\mathrm{m}^{3}$

Contained $\mathrm{Pu}, \mathrm{kg} \quad 0.24$

liadioactivity, MCi $\quad 0.03$

Mixed oxide fuel waste

Volume (in concrete), $\mathrm{m}^{3}$

Contained $\mathrm{Pu}, \mathrm{kg} \quad 0.65$

Radioactivity at 20-year cooling 
Before leaving the subject of waste from reprocessing commercial fuel, it should be noted that the Nuclear Fuel Services plant at West Valley, NY processed 640 tonnes of fuel (280 tonnes of commercial) in the period 1966 to 1972. The high-level waste from these operations is stored as liquids in tanks (2300 cubic meters from uranium fuels as a neutralized liquid and 45 (qubic meters from thorium fuels as an acidic liquid) pending decisions ${ }^{4}$ on future treatment/disposal.

The characteristics of this waste are quite similar to those of defense wastes to be described later, as are the currently available stabilization technologies to be described in the following paper by Goetz Oretel.

\section{COMMERCIAL WASTE CHARACTERISTICS}

The characteristics of commercial wastes of principal interest for geologic disposal are heat generation, toxicity and mobility.

Both spent fuel and high-level waste at 10 years from reactor have a heat generation rate of $1.1 \mathrm{~kW}$ per original metric ton of heavy metal. They decay at the same rate during the time the short-lived fission products are dominant. In the long term, the extra uranium and plutonium in the spent fuel keep the heat generation rate of spent fuel some threefold above the $20 \mathrm{~W} / \mathrm{MT}$ of high-level waste at 1000 years. In practical terms this would indicate an extra temperature rise ${ }^{(5)}$ in the repository horizon of $1^{\circ} \mathrm{C}$ for spent fuel compared to high-level waste for every watt per square meter of areal loading.

Regarding toxicity and thus potential risk, the technical evidence indicates that the water ingestion hazard index of spent fuel or highlevel waste is quite similar to the water ingestion hazard index of natural ore bodies. For example, the toxicity index--expressed as the quantity of water required to dilute soluble species to drinking water tolerances--of both spent fuel and high level waste aged 1000 years is less than an equivalent volume of natural ores of mercury, pitchblende, chromium, selenium, lead and cadmium. I believe most people will agree that man can engineer near total containment for this period and probably longer.

Very few data exist for comparing the behavior of natural ore bodies to nuclear waste under pertubations, in the geohydrology. However, the mobility of selenium has been reported $(7)$ to be one lundred times that of plutonium. 


\section{DEFENSE WASTES}

The defense wastes at Idaho, Hanford and Savannah River that might be destined for geologic disposal are the high-lezyel and transuranic contaminated wastes and the separated ${ }^{90}$ SR and ${ }^{3}$ Ce at Hanford.

Currently, the high-level wastes (liquids, sludges and calcine) have a volume of $380,000 \mathrm{~m}$ and an activity of $800 \mathrm{MC} \mathrm{i}$. The activity is two and one-half-fold less than that currently in spent fuel from the commercial nuclear power sector.

If the current activities in the defense sector were continued until 1990 and if the high-level wasţes were segregated and solidified, their volume would be about $27,000 \mathrm{~m}^{3}$. If this were packaged in the $0.68-\mathrm{m}-$ diam by 3.5-m-long configuration being considered by Savannah River, some 37,000 canisters of waste would result.

Heat generation rates, however, would be modest, about $1 \mathrm{~kW}$ per canister for 5-year aged HLW and substantially less for the old inventories.

It is estimated that by 1990,1010 strontium and 2970 cesium capsules will be available at Hanford. These capsules are relatively small, about $7 \mathrm{~cm}$ in diam by $53 \mathrm{~cm}$ long, but collectively represent $1600 \mathrm{~kW}$ of heat.

The defense transuranic waste buried or stored at Hanford, Idaho, Los Alamos, Oak Ridge and Savannah River at the end of FY 1978 is about $420,000 \mathrm{~m}^{3}$ containing about one metric ton of transuranics. If exhumed and subjected to a tenfold volume reduction, it would represent 270,000 drums (200-1iter) with an average TRU content of $5 \mathrm{~g}$ for a geologic repository.

The exact form of the treated TRU has nct been determined. Candidates range from simple packaging of the residues from pyrolysis, incineration or acid digestion to incorporation in concretes or glasses. 


\title{
RADIOACTIVE WASTE TREATMENT TECHNOLOGY
}

\author{
Ray D. Walton, Jr. \\ U.S. Department of Energy \\ Washington, D.C.
}

\section{Introduction}

Bridging the gap between radioactive waste generation and isolation are those steps or processes required to convert the waste to a chemical and physical form ard container suitable for transportation and isolation. This paper summarizes DOEsponsored technology development programs for the treatment and packaging of highlevel waste (HLW), and transuranium-contaminated solid waste (TRU). These two waste types were selected because they have been recommended for geologic waste isolation by the Interagency Review Group Report to the President on Nuclear Waste Management (TID-28817 draft).

In each treatment, the primary goal is to place the waste in a form and container which is acceptable to the Federal repository or other waste disposal facility. Desired benefits resulting from these waste treatment processes iriclude: reduction of fire risk from combustibles; limiting gas generation; reduction in the risk of dispersion during handling, transportation or isolation; and conservation of space in the isolation facilities. Wasta form is one part of the total system consisting of waste form, container and location, isolating the waste from man and his environment.

A fundamental requirement for each of these waste treatment processes is the protection of the environment and the health and safety of the workers and of the general public. All laws and regulations establishing requirements for Federa] organizations and their contractors will be complied with by DDE. One of these Taws, the National Environmentai Policy Act of 1969 (NEPA) requires a detailed statement to be published concerning any major Federal action that significantly affects the environmient. All plans and goals reviewed in this presentation will be firlalized only after completion of all NEPA requirements.

Lead DOE field office/contractor teams have been designated for long-term management of HLW (Savannah River/DuPont) and TRU (Albuquerque/Rockwe11-Rocky Flats). These 
lead organizations are responsible for pianning and coordinating the tocal U.S. DOE development program for that specific type of waste within the guidelines established by the DOE Headquarters Division of Waste Products.

Nuclear waste treatment technology programs for HLW and TRU waste will be discusser. For each waste type, program objective, strategy, accomplishments and programmatic milestones will be covered.

\section{HIGH-LEVEL WASTE TECHNOLOGY DEVELOPMENT}

Most of the existing high-level wastes in the United States have been generated in defense activities. About 70 million gallons of these wastes are currently stored as liquids or bulk solids in underground tanks or bins at the Hanford, Savannah River and Idaho plants. Despite well publicized leaks and spills, no radiation injuries or serious radiation exposure to members of the public have resulted from this storage, nor have significant amounts of waste escaped the storage sites in over 30 years of operation. However, such storage does require continued surveillance and regular replacement of containment facilities. Another 0.6 million gallons of commercial high-level waste is stored in tanks at the Nuclear Fuel Services chemical processing plant at West Valley, NY. No additional commercial waste will be produced under the current policy on spent commercial reactor fuels.

The primary objective of the DOE long-term high-level waste management program is to protect public health and safety. Further, this is to be accomplished with minimum reliarice on man for maintenance and surveillance. A secondary objective is to develop a technology base for immobilization of existing high-level wastes and the evaluation of alternative fuel cycles.

The DOE strategy for selecting HLW management alternatives and the immobilization of high-level wastes are summarized in Figure 1. The overall plan and milestones for implementing this strategy are shown in Figure 2. This plan represents a schedule, which is achievable with a concentrated effort, expeditious decisions and adequate funding.

An important need at this time is the initial immobilization criteria which will assure that the waste form and canister will be compatible witn the total transportation, handling and repository system. Recent emphasis holds that the waste form and canister must provide a part of the total system of isolation during geolngic storage as well as during handling and transportation. While the criteria are being deve?oped, DOE is continuing to strengthen current programs on immobilized waste form development, waste characterization and is developing further the design concepts for full-scale immobilization processes. Current studies cover several alternative processes leading to stable, immobile forms for high-level wastes. Candidate waste immobilization product forms include glasses, synthetic minerals, concretes, calcines, ceramics, and matrices such as ca? cine particles in a metal substrate. Studies are continuing in private as well as in DOE laboratories to determine the optimum physical structures and fabrication methods for these various forms and their expected radionuclide release rates during fabrication, shipment and storage. Definition of repository media, temperature, pressure, etc. are critical to this effort. Where possible, DOE laboratories will consider and cooperate with the waste immobilization studies being carried out in a number of other countries. DOE waste treatment programs are being conducted in close coordination with waste isolation programs, which will establish the conditions that immobilized waste forms should be designed to withstand. Formal review of the DOE waste immobilization program is provided by internal DOE and prime contractor reviews, ad hoc interagency task force (IRG), 
detailed consultant review by organizations such as A. D. Little, and by independent organizations such as the National Academy of Sciences.

The DOE plan provides for an integrated research and development effort as well as program documentation and publ ic interaction at each of the DOE sites where waste is currently stored. As the site programs are different because the chemical and physical forms of the waste, geographic location and erivironmental considerations are site-specific, the national program will assure appropriate technology transfer.

Based on these research, development and public interaction programs, a decision will be made on a first-generation immobilization form and processing method for the Savannah River high-level waste by the end of FY 1981, and corstruction of a Savannah River waste processing facility could begin as early as FY 1982 . The first immobilized waste would be available for shipment to a Federal repository in FY 1989. Successful operation of such a waste immobilization and interim storage facility at Savannah River would constitute the first full-scale implementacion of high-level waste immobilization.

Strategy calls for appropriate immobilization at the Savannah River, Hanford and Idaho sites. Separate facilities may be required because it is impractical to ship high-level liquid waste.

Key milestones for the Savannah River immobilization facility include: process selection by the end of FY 1981, construction in or about FY 1982 and operation as early as FY 1988. Development of definitive waste form performance criteria and completion of a well coordinated initial assessment of immobilized waste forms by the end of FY 1981 are needed to select the final steps in the Savannah River process. It is expected that several more years of research and development on alternate forms and processes will be required even after this initial assessment is completed. It is also probable that immubilization forms will have to be tailored toward particular wastes. Process selection and construction of facilities for Idaho and Hanford wastes are expected to begin by FY 1987 and FY 1988, respectively.

Our efforts over the past two years (Figure 3) have mainly been directed at assessing the technical alternatives available at each of the DOE waste storage sites along with the costs and risks associated with each alternative. Also, DOE has maintained a strong research and development effort on problems related to these al ternatives and on several promising waste forms. Because glass is currently the best developed technology in this country and abroad, and because it appears adequate for defense wastes, large-scale calciner-melter tests and radioactive product dernonstrations are well underway at Pinl and elsewhere.

In FY 1979 (Figure 4), we plan to continue our site-specific assessment of alternatives and our research and development effort. We will also greatly expand the research and developiient program on crystalline and other alternative waste forms, and start a more coordinated effort to develop waste form performance criteria. Engineering-scale development on glass will continue at PNL and at SRP. A key 1979 milestone is installation of a production-scale melter at SRP.

In summary, a research, development and demonstration program is fundamental to implementation of our long-term high-level waste management strategy.

\section{TRU-CONTAMINATED SOLID WASTE TECHNOLOGY DEVELOPMENT}

TRU-contaminated solid waste contains transuranic nuclides above a threshold concentration of 10 nanocuries per gram. This working threshold is currently under 
review by the Department of Energy. Within DOE's operations, waste below this threshold level is considered "low level" and acceptable for shallow land burial.

Because of its radioactivity, plutonium-239 with a half- 1 ife of 24,000 years is the nuclide of principal concern in TRU waste. Defense TRU waste had been routinely disposed of by shallow land burial at DOE sites until 1970 when AEC decided to store it retrievably periding a decision on its permanent disposition.

The primary objective of the TRU program is to develop the waste treatment technology required to achieve long-term isolation of TRU-contaminated wastes at an early date. DOE's strategy is to develop technology for safely and economically treating TRU wastes to meet anticipated criteria for long-term isolation. Such technology includes volume reduction (compaction, crushing, digestion or combustion), immobilization of residues, and decontamination of metallic surfaces to reduce waste quantities.

Compacting is a process that is simple and works reasonably well for low-density materials. Crushing works for glass, and large metal objects can usually be cut into pieces for tighter packing. Even better for many wastes, however, is some form of digestion or combustion; and we are looking at several options. Keep in mind that all of thise processes must be carried on in closed systems so that radioactive materials, particularly airborne species, are contained. The fluidized-bed incinerator suspends the contaminated material in a loose bed such as sodium carbonate salt which reacts with acids, chlorides, etc. and where combustion is very efficient. The cyclone iricinerator burns solid wastes in a swirling air stream. Controlled-air incineration, similar to the process used in air-tight wood-burning stoves, is another alternative we are investigating. Still another is the slagging pyrolysis incinerator, which accepts metai and contaminated soil as part of the waste stream and leaves the residue as a stable brick of slag. Other processes receiving attention are acid digestion and anaerobic bacterial digestion. Each of the technologies must be evaluated in terms of its ability to consume different waste inputs. The effluents from each are also being compared.

Most of the volume reduction processes result in an ash, a fine powder, or a sludge. Immobilization of resulting ashes, residues and sludges may be necessary to meet the geologic repository waste acceptance criteria. Technology is being developed to produce a high-density solid that is rugged enough to be handled without damage, with individual pieces large enough that they cannot become airborne or scattered too widely for easy recovery, and with physical and chemical properties that prevent release of the radioactive material to the surrounding geoiogic environment. Furthermore, the immobilized form should not be degraded by interaction with its geologic environment and it should not release large quantities of gas.

The major portion of radioactive waste immobilization development work has been directed toward incorporation of the waste into a glassy solid - vitrification. Since research into vitrification has been going on for many years, we are now at the stage of trying to improve different processes and learn more about the long-term stability of glass as a waste form. Other forms include ceramics, slag, plastic, bitumen (an asphalt-like material), and cement. Techniques being developed include pelletizing and sintering the powder, as well as encapsulating it in plastic.

It is expected that the volume reduction (incineration, etc.) technology development phase will be completed with major hardware experimentation by 1981 to show that these processes can be adapted for operations if selected. Recent accomplishments and Fi 1979 milestones are listed on Figure 5 . 
Implementation plans for the TRU solid waste treatment program include technical aiternative and NEPA-related documents as well as construction of processing units. Each DOE operations office with a significant quantity of buried and/or stored TRUcontaminated solid waste (ID, SR, LASL and RL) will issue a document which shows the technical alternatives for the long-term management of its TRU waste. Idaho's document was issued at the end of 1978.

It is expected that alternative documents will be followed by progranmatic environmental impact statements (PEIS) which will support major decisions such as "leave or retrieve" for buried waste. Because these are NEPA documents, they will be issued as Irafts, commented upon and then finalized. Eventually, project-specific EIS or environmental assessments will be prepared for any major construction program to provide treatment facilities for the TRU waste. Figure 6 provides a schedule for these documents.

Several types of TRU treatment facilities are planned at Idaho, Savannah River, LASL and Richland. These include a slagging pyrolysis incinerator (ID), electrically heated controlled-air incinerator (SR), a gas-fired controlled-air incinerator (LASL), and a cyclone incinerator for solvent waste (HEDL). Tho currently constructed units, rotary kiln and agitated hearth incinerators, at Rocky Flats will be placed in operation during the next two years. Figure 7 shows the expected timing for these units.

\section{Conclusions}

DOE has designated lead organizations to direct and coordinate total DOE programs for nuclear waste treatment technology development for high-level and TRU waste. During FY 1979, program strategy documents will be issued covering the total programs for each of these waste types. Close coordination is being maintained Detween waste generators, waste process development and waste isolation programs. All of these programs are contained within the DOE Office of Nuclear Waste Management and have been reviewed by the Nuclear Waste Management Interagency Review Group.

Urgently needed at this time are high-level and TRU solid waste repository waste acceptance criteria and a definition of repository environmental conditions. Each waste form must be designed to meet repository performance criteria under expected temperatures, pressures, moisture, chemical constituent, etc. conditions. Plans are being formulated for a waste form characterization laboratory to test and assure the waste forms meet repository conditions.

Near- and long-term safety is a primary concern of the program. Each process and/or facility will be built and operated in a manner that all required safety, environmental and public health standards are met and maintained. In addition, the goal is to assure the long-term confinement of these wastes is accomplished with minimum reliance on man for maintenance and surveillance.

Development and selection of optimum long-term waste forms continue to be challenging issues; however, safe and cost-effective methods for producing suitable waste forms and containers are being developed, repository waste acceptance criteria are being developed, and an orderly process has been established to complete development, select and implement the programs required to produce acceptable waste forms. 


\section{HIGH-LEVEL WASTE STRATEGY}

- Assess and select waste management alternatives for each DOE defense high-level waste site

- Conduct research and development on issues associated with site alternatives and on promising waste forms

- Develop waste form performance criteria and standard testing methods

- Develop full-scale experience, design and cost data on a practical and acceptable waste immobilization system

- Treat existing DOE high-level wastes and select disposal method

- Develop technology base for immobilizing existing commercial wastes

- Evaluate waste management needs for alternative power reactor fuel cycles

Figure 1

\begin{tabular}{|c|c|c|c|c|c|}
\hline \multicolumn{6}{|c|}{ DOE HLW IMMOBILIZATION PLAN } \\
\hline & $\begin{array}{c}\text { Process } \\
\text { Development } \\
\text { and Selection } \\
\end{array}$ & $\begin{array}{c}\text { Public } \\
\text { Interaction }\end{array}$ & $\begin{array}{l}\text { Facility } \\
\text { Design } \\
\end{array}$ & $\begin{array}{c}\text { Facility } \\
\text { Construction }\end{array}$ & $\begin{array}{r}\text { Facility } \\
\text { Operation }\end{array}$ \\
\hline Savannah River & $1977-82$ & $1977-87$ & $1980-86$ & $1982-88$ & $1988-2018^{*}$ \\
\hline Hanford & $1977-85$ & $1977-93$ & $1986-93$ & $1988-94$ & -- \\
\hline Idaho & $1977-83$ & 1977-91 & $1985-91$ & $1987-92$ & -- \\
\hline Commercial & $1973-86$ & $1978-86$ & - & -- & $\cdots$ \\
\hline
\end{tabular}

* Backlog of stored waste would be processed by 1998 . Current generation waste would be processed after that date.

Figure 2 


\section{Assessments}

- Issued long-term management documents on HLW alternatives for Savannah River, Hanford and Idaho

- Issued draft programmatic environmental impact statement for Savannah River

Research and Development

- Completed small-scale sludge handling and vitrification tests at SRP

- Started large-scale vitrification tests at PNL with simulated SRP wasto

- Initiated development of pelletized ceramic and glass waste forms for Idaho wastes

- Continued assessment of cement as waste form at ORNL

- Incorporated synthetic Savannah River and commercial wastes into cermets at ORNL

\section{Facilities}

- Designed prototype waste retrieval systems at Idaho and Hanford

- Installed large-scale radioactive waste vitrification product demonstration equipment at PNL

- Installed hot demonstration equipment for removal of sludge from SRP waste tanks with recycled supernate

- Completed conceptual design and venture guidance cost appraisal for waste processing facility at SRP

Figure 3 
LONG-TERM HIEH-LE!EL WASTE MANAGEMENT MILESTONES

FY 1979

\section{Assessments}

- Issue draft programmatic environmental impact statements for Hanford and Idaho

- Issue final programatic environmental impact statement for SRP

- Issue report on continued storage of high-level waste in Hanford tanks

- Initiate development of waste form performance criteria and standard testing methods with private industry or university

Research and Deveiopment

- Continue large-scale vitrification studies and radioactive glass product demonstration at PNL

- Publish report of borosilicate glass development by PNL

- Continue ORNL development of cermet and cement waste forms

- Initiate study of crystalline ceramic waste forms with private or university laboratory

\section{Facilities}

- Install prototype calciner/vitrification system at SRP

- Start Title-I and II design for waste processing facility at SRP

- Complete design and installation of pel letization pilot plant at IJaho

- Complete removal of sludge from one SRP waste tank

- Start acquisitic-; and analysis of waste samples from Hanford tanks 
TRANSURANIUM-CONTAMINATED WASTE VOLUME REDUCTION PROJECTS

Project Title

ACID DIGESTION

CONTROLLED AIR

INC INERATION

\section{CYCLONE AIR \\ INCINERATION \\ SLAGGING PYROLYSIS \\ INCINERATION}

\section{FLUIDIZED-BED}

INCINERATION

\section{Fy 78 Accomplishments}

Started up and operationally tested Radioactive Acid Digestion Test Unit. Feasibility tests conducted for processing organic liquids and ion exchange resin.

Completed Controlled-Air Incineration operational testing with nonradioactive wastes.

Demonstrated Cyclone Air Incineration with TRUcontaminated combustible waste.

Evaluated incinerators and selected slagging pyrolysis unit. Initiated incinerator and facility designs.

Established pilot plant incinerator operation on sol id waste. Liquid waste incineration was tested.

\section{FY 79 Milestones}

Initiate processing of lowlevel TRU combustible waste. Test feasibility of processing organic liquids and resins.

Complete Controlled-Air Incineration demonstration runs using transuraniumcontaminated solid waste.

Demonstrate on special wastes, i.e., ion exchange resin, sludge, etc.

Complete conceptual design for incinerator and facility.

Complete HEPA filter and ion exchange incineration tests. Install compression feeder on pilot plant.

Figure 5 
LONG-TERM MANAGEMENT PROGRAM FOR TRANSURANIC-CONTAMINATED SOL_ID WASTE

\begin{tabular}{|c|c|c|c|c|}
\hline & \multicolumn{4}{|c|}{ Publication Schedule - Fiscal Years } \\
\hline & $\underline{I D}$ & $\underline{\mathrm{SR}}$ & $\underline{\text { LASL }}$ & $\underline{\mathrm{RL}}$ \\
\hline Alternatives Document & 1079 & 1080 & 3080 & 1081 \\
\hline Programmatic EIS - Draft & 2080 & 1081 & 3082 & $3 Q 82$ \\
\hline Programmatic EIS - Final & $2 Q 81$ & 1Q 82 & 3083 & 3083 \\
\hline
\end{tabular}

TRANSURANIC WASTE TREATMENT - MAUOR UNITS

Construction - Fiscal Year

\begin{tabular}{|c|c|c|c|c|c|}
\hline & $\underline{\text { Site* }}$ & Project & Initiation & Completion & Operational \\
\hline Rotary Kiln & RF & 71 & 74 & 79 & 81 \\
\hline Agitated Hearth & RF & 71 & 74 & 79 & 81 \\
\hline Controlled Air/Electric Heat & SR & 81 & 81 & 83 & 84 \\
\hline Controlled Air/Gas & LASL & 81 & 83 & 87 & 88 \\
\hline Slagging Pyrolysis & ID & 82 & 82 & 86 & 86 \\
\hline Cyclone Drum (solvent) & HEOL & 81 & 81 & 83 & 84 \\
\hline
\end{tabular}

*RF - Rocky Flats; SR - Savannah River, LASL - Los Alamos Scientific Laboratory, ID - Idaho, HEDL - Hanford Enginerering Development Laboratory 
GEOLOGIC SITING CONSIDERATIONS FOR THE DISPOSAL

OF RADIOACTIVE WASTE INTO SUBMARINE

GEOLOGIC FORMATIONS

Charles D. Hollister

Woods Hole Oceanographic Institution

Woods Hole, MA 02543

\section{INTRODUCTION}

Before selecting a generic submarine repository study site for any radioactive waste one must complete the exercise of establishing, and then ranking, site suitability conditions.

In this preliminary effort, to identify submarine geologic formations that appear most suitable in an enviroment of maximum stability the following media and site characteristics appear desirable:

\section{THE GEOLOGIC MEDIUM IS THE PRIME BARRIER TO RELEASE}

It is the fundamental working criterion that the "host medium" or geologic medium remains the single most important barrier to the release of radioactive material to the biosphere. This broad generalization leads to the two most important retention aspects of the host medium--high sorption capability and low permeability.

A. The distribution (or sorption) coefficient) (Kd) of the host medium is a measure of its ion uptake capacity. The distribution coefficient is simply the ratio of the amount of material (radicactive ions in this case) that is bound to the medium to the amount that is free to travel in the pore water through the medium either by diffusion or advection. A Kd of I implies that for every ion locked up one is mobile; a $\mathrm{Kd}$ of $10^{6}$ says that the ratio is a million locked up to one that is mobile. Kd values are related to grain size amongst other parameters, i.e. the finer grained sediment have the highest $\mathrm{Kd}^{\prime} \mathrm{s}$. A high Kd for a broad range of elements is one of the key desirable characteristics of a disposal medium. 
B. Another important characteristic is permeability, the measure of the speed with which fluids can migrate through a medium. For waste retentior, low rates of flow are desirable. Permeability should not be confused with porosity which is simply the measure of pore space in a medium. The important point is that a medium such as a fine grained clay may be very porous but have a very 10 w permeability because the pores are not connected. A medium (such as silt or sand) may have a comparatively lor porosity but be highly fermeable if its fabric includes a large fraction of interconnecting pore spaces.

C. Another desizable characteristic of the medium is that it should behave plastically or as a viscoelastic medium to enhance its integity if disturbed. Such plasticity also could produce self-healing of an emplacement hole.

D. The role of organic material in processes of remobilization is unknown due to the difficulty of modeling the effect of organics in complexing ions and thus preventing their sorption by the sediment. Dur initial studies have focused on sediments with the least amount of organic material.

E. Another even less well understood (or quantifiable) characteristic of the medium is its ability to remain undisturbed under high or variable thermal stress. That is to say, it is necessary to understand the mediun's behavior under a variety of thermal fields in order to predict its response as a function of temperature and time. A fundamental question her: is whether the existence of a heat source in the repository could cause the sediment to convect and thereby breech the sedimentary barrier. are:

F. In summary, the most desirable characteristics of the "host medium"

1. Low permeability and high $\mathrm{Rd}$,

2. ability to self heal, i.e. be visco-elastic in response to dynamic stress,

3. stability under predicted thermal loading,

4. a low content of organic matter, i.e. be well oxidized.

The submarine geologic formation that appears to best satisfy the above criteria is abyssal "red" clay. Depending on organic interactions and permeability considerations, light brown deep-sea clays with $20-40 \% \mathrm{CaCO}_{3}$ also may be suitable. Increasingly organic-rich, more permeable biogenic oozes appear less suitable, with turbidite sands and silts least desirable of all.

Thus for the time being the U.S. Seabed Program is not considering areas known to contain geologic formations with the following characteristics:

(a) Coarse grained deposits such as the proximal portions of abyssal plains (including all fracture zone floors), and ponded turbidite sands of intermountain valleys that are expected to have high permeabilities and low Kd's and are least likely to behave plastically. This criterion effectively eliminates all submarine canyons, continental shelves, shallow portions of the Mid-Oceanic Ridge and fracture zone floors. 
(b) Deposits exhibiting high or variable thermal conductivity or where heat flow gradients are non-linear. These regions lack coherency of thermal properties which probably reçlect variations in geotechnical properties, most probably bulk permeability. It is teo early in the program to review all heat flow data in order to exclude areas on a global scale; rather it seems prudent to do the exclusion exercise on a larger scale with other more general exclusion criteria and then to review heat-flow data and perhaps conduct special heat flow cruisez in candidate regions.

(c) Deposits with high organic carbon content in order to avoid the nonpredictable behavior of chelated radioactive isotopes. This criterion would probably eliminate the continental rise and slope where organic carbon content of the upper 10's of meters of hemipelagic material range between 1 and 10\%.

(d) Sediment thickness of less than 50 meters. From initial calculations and from experience with the free fall Giant Piston corer it appears that a penetrometer will reach between 20 and 40 meters depth below bottom in the types of sediment that fit the above selection criteria. Because of the high and variable bulk permeability that have been determined for at least the upper layers of oceanic crustal basalt a buried container should be well clear of basement.

\section{THE OPTIMUM GEOLOGIC ENVIRONMENT FOR THE MEDIUM SHOULD BE TRANQUIL AND PREDICTABLE.}

This aspect of the assessmen:-i.e. setting or environment as contrasted with medium characteristics, also yields constraints based on certain working assumptions. The most important of these is environmental predictability over the minimum time span needed for waste isolation (i.e. $10^{5}$ years). $3 y$ this it is meant that the goal is to be able to predict, with high levels of confidence, the probability of a natural event occurring at a repositozy that would alter, in a detrimental way, its suitahility as a repository. The initial approach has been and still is, to identify areas of low geologic activity, i.e. geologically tranquil regions with very low seismic and volcanic (tectonic) activity and a long history of continuous deposition. Such regions are found in the centers of the large lithospheric plates.

Thus one of our site exclusion criteria is proximity to the edges of lithospheric plates. This excludes those areas within 100 miles of any recorded seismic event greater than magnitude $x^{1}$ or within 100 miles of volcanoes that are known to have been active over the past $10^{7}$ years. All deep-sea trenches, mid-ocean rift valleys, the crests of the Mid-oceanic Ridge, and zones of transform faulting are excluded from consideration.

Another geologic perturbation that affects the earth is recurring iceages. Present trends suggest that another ice age will occur within the next 5,000 to 50,000 years. This is less than the $10^{5}$ year isolation period

1 This value will be established after completion of our geotechnical/ dynamic response program. 
specified above and thus regions likely to be adversely affected by another ice age should be excluded from consideration. These areas include all major sills between the Norwegian Sea and the North Atlantic, all areas known t: have experienced ice-age erosion and all deposits containing coarse, icerafted debris.

Because eventually man wiil seek any natural resource of value, all regions containing known or suspected concentrations of food, minerals or hydrocarbons should be excluded. This includes regions where sand or gravel can be or may be mined (i.e. all continental shelves). From the point of future hydrocarbon recovery entire continental margin including deep sea fans, cones and aprons should also be excluded.

In addition, regions below areas of high biological productivity, such as upwelling areas, which support major fisheries, are exciuded and regions of manganese nodules rich in nickel and copper are also excluded. Inasmuch $\leq s$ these surficial deposits could be mined in advance of a disposal operation however this criterion might be relaxed in the future.

Regions crossed or occupied by (1) telecommunication cables, (2) major shipping lanes, or (3) defense installations are excluded.

In addition to the above considerations, there are certain technical low level waste criteria governed by the IAEA recomendations (IAEA INF CIRC/205/Add. 1/Rev. 1, August 1978) that should be taken into consideraticn. Most of these are covered above by the high level waste criteria, but they are listed here for completeness. The HLW program will probably ignore criteria 非.

1. Sites should lie between $50^{\circ}$ North and $50^{\circ}$ South latitude.

This criterion is designed to avoid sources of bottom water which are characterized by strong vertical mixing, and areas of high biological productivity in the polar regions. Ice rafting is also a concern in such areas. (Section c.2.1(2))

2. Depth at the site should be 4000 meters or more.

This criterion is derived from the fact that biological, chemical, physical and topographical gradients generally decrease below $4000 \mathrm{~m}$; bottom water circulation is slower; and organic carbon in the pelagic sediments of such areas tends to be low. This criterion is also motivated by a desire to be clear of continental margins.

3. Sites should be remote from continental margins.

This criterion is designed to avoid regions of high biological productivity, active resource exploration and exploitation, and geologic unpredictability and instability (continental slope, rise and associated fans and canyons). (Section C.2.1(3))

4. Sites shouid be away from areas of potential seabed resources. This criterion is designed to minimize the likelihood of future disturbances which might shorten pathways to man, and to avoid possible conflicts in "land" uses. (Section C.2.1.(5)) 
5. Sites should be away from transoceanic cables in use.

This criterion is intended to avoid disturbances and conflicts in uses.

(Section C.2.1.(4))

6. Sites should be away from areas where geologic hazards such as subrnarine slides, volcanoes and earthquakes, decrease a site's environmental predictability.

This criterion is designed to reduce the likelihood of unpredicted disturbances which might shorten pathways to man. (Section C.2.1.(3))

7. The area of a site should be defined by precise coordinates, with an area as small as practicable.

This criterion appears to be motivated by a desire to limit the affected area. (Section C.2.2)

8. If possible, sites should be in areas covered by precise navigational aids. This criterion is intended to assist in relocating the site for monitoring purposes. (Section C.2.1.(7))

9. Sites should be away from areas, such as submarine canyons, which may unpredictably affect rates of exchange of deep waters and organisms with surface waters near the continental shelf.

This criterion is intended to avoid shortening of the pathways to man. (Section 2.8.3 of Appendix)

10. Sites should be chosen for convenient conduct of operations and to avoid, so far as possible, the risk of collision with other traffic and undue navigational difficulties..

This criterion is specified to minimize hazards to navigation and safe operations at the site. (Section C.2.1.(7))

11. Bottom current shear stress should not exceed critical erosional shear stress.

This is designed to prevent high rates of resuspension of sediments at a site and the eroding of the geologic barrier.

III. SUMMARY OF OCEAN REGIONS EXCLUDED (AT THIS TIME) FROM CONSIDERATION AS A HIGH LEVEL WASTE RADIOACTIVE WASTE REPOSITORY: ${ }^{2}$

1. areas less than 4000 meters deep,

2. the continental margin including fans, deltas, aprons, cones,

3. proximal portions of abyssal plains,

4. all fracture zone abyssal plains,

5. all submarine canyon-levee systems,

6. areas covered with less than 50 meters of sediment,

7. areas greater than 100 nautical miles from plate boundaries,

8. areas with ice-rafted debris,

9. major shipping lanes, cable routes and defense installations,

10. seafloor regions below areas of high biological productivity,

11. approximately one third of the world's ocean floor satisfy these criteria.

2 Ranking is not implied at this point in this preliminary siting effort. 
24 
ION TRANSPORT IN DEEP-SEA SEDIMENTS

G. Ross Heath

School of Oceanography, Oregon State

University, Coryallis, Oregon 97331

\section{INTRODUCTION}

The transport or migration of dissolved ions (specifically radionuclides) in the sediments of the deep seabed differs from the analogous processes in most proposed terrestrial geologic disposal sites. Deep-sea pelagic clay, which is the most plausible disposal medium, is saturated with a 3.5 percent brine solution. Because of the lack of fractures, extremeiy fine particle size, and virtual absence of lateral hydrostatic pressure gradients or unstable stratification, molecular diffusion is likely to be more important than advection in the dispersal of dissolved ions.

\section{ADVECTION}

\section{Inperturbed Environment}

In the absence of a heat source or severe physical disruption of the disposal site, the only force tending to produce pore-water flow is continuing sedimentation which tends to compact the underlying deposits. The vertical velocity of the pore waters due to compaction is greatest at the sea floor, but less than the sedimentation rate. Thus, for the central North Pacific, for example, pore water velocities must be less than $10^{-1} \mathrm{~cm} / \mathrm{sec}$. From the riewpoint of disposal-site integrity, such advection could never carry dissolved nuclides up to the ocean because the sea floor grows upward faster than the pore water can migrate.

The reality of this situation is confirmed by samples from the deep-seabed collected by the Deep Sea Drilling Project. The profiles of dissolved ions derived from specific levels (strontium from a carbonate ooze layer in a clay sequence, for example) can be modeled exactly by considering only molecular diffusion and the 
accumulation rate of the sediment column - no additional advective term is required (McDuff and Gieskes, 1976).

\section{Perturbed Environment}

The impact of a buried heat source (such as a cannister of radioactive waste) on the circulation in a deep-sea clay has been addressed by Hickox (1977) and is being further studied by D. McVey and co-workers of Sandia Laboratories and A. Silva and co-workers at the University of Rhode Island.

Preliminary calculations, using typical properties of North Pacific deep-sea clays (thermal diffusivity $0.0023 \mathrm{~cm} 2 / \mathrm{sec}$, permeability $1.48 \times 10^{-11} \mathrm{~cm}^{2}$, coefficient of thermal expansion $2.55 \times 10^{-4}$, viscosity $0.018 \mathrm{~g} / \mathrm{cm} \mathrm{sec}$, density $1.02 \mathrm{~g} / \mathrm{cm}^{3}$, and specific heat $3.41 \mathrm{~J} / \mathrm{g}^{\circ} \mathrm{K}$ ) and a heat source decaying exponentially from 1000 to $10 \mathrm{~W}$ over a period of 10,000 years, suggests that even a water particle right against the upper surface of the hot cannister will be displaced less than $50 \mathrm{~cm}$ by thermally induced convective flow of the pore waters. This surprising result reflects primarily the extremely low permeabilities of deep-sea clays. clearly, the absence of fractures in such clays (which respond visco-elastically to imposed stresses) is a key factor in their ability to suppress convective flow.

The model results to date are encouraging. More experimental work, particularly addressing the near-field $\left(>100^{\circ} \mathrm{C}\right)$ effects of temperature on the physical properties of deep-sea clays is called for, however, before we can completely dismiss the convective transport of ions as a breachment mechanism of concern.

\section{DIFFUSION}

\section{Unperturbed Environment}

For an ion diffusing from a source (such as a disintegrating buried cannister of waste) to a sink (such as the oceari), the characteristic diffusion time is simply the square of the source-sink distance divided by the diffusion coefficient of the ion in the intervening medium. Many cations have diffusiori coefficients in deepsea clays at ambient temperatures of the order of $3 \times 10^{-6} \mathrm{~cm}^{2} / \mathrm{sec}$. Thus, a burial depth of 30 meters yields a characteristic diffusion time of $3 \times 10^{12}$ seconds or 100,000 years.

This calculation assumes that there is no interaction between the dissolved ions and the sediment through which they are diffusing. Such an assumption is demonstrably incorrect. Numerous experiments during the last twenty years have shown that cations, particularly heavy metals, are strongly sorbed by deep-sea clays. The extent of such sorption can be described by a distribution coefficient ( $K_{d}$ ) which is the ratio of sorbed to dissolved ions in a specified volume of saturated sediment. In the concentration range we are concerned with, the distribution coefficients of metal ions are strongly negatively correlated with concentration (Fig. 1). Thus there is no single distribution coefficient for a given ion in a given deep-sea clay. Typically, however, our work and that of $K$. Erickson at Sandia indicates $K_{d}$ values in the $10^{3}-10^{6}$ range for micromolar solution concentrations. The distribution coefficient has a direct multiplicative effect on the characteristic diffusion time of an ion. In other words, if the ion considered in our earlier example has 


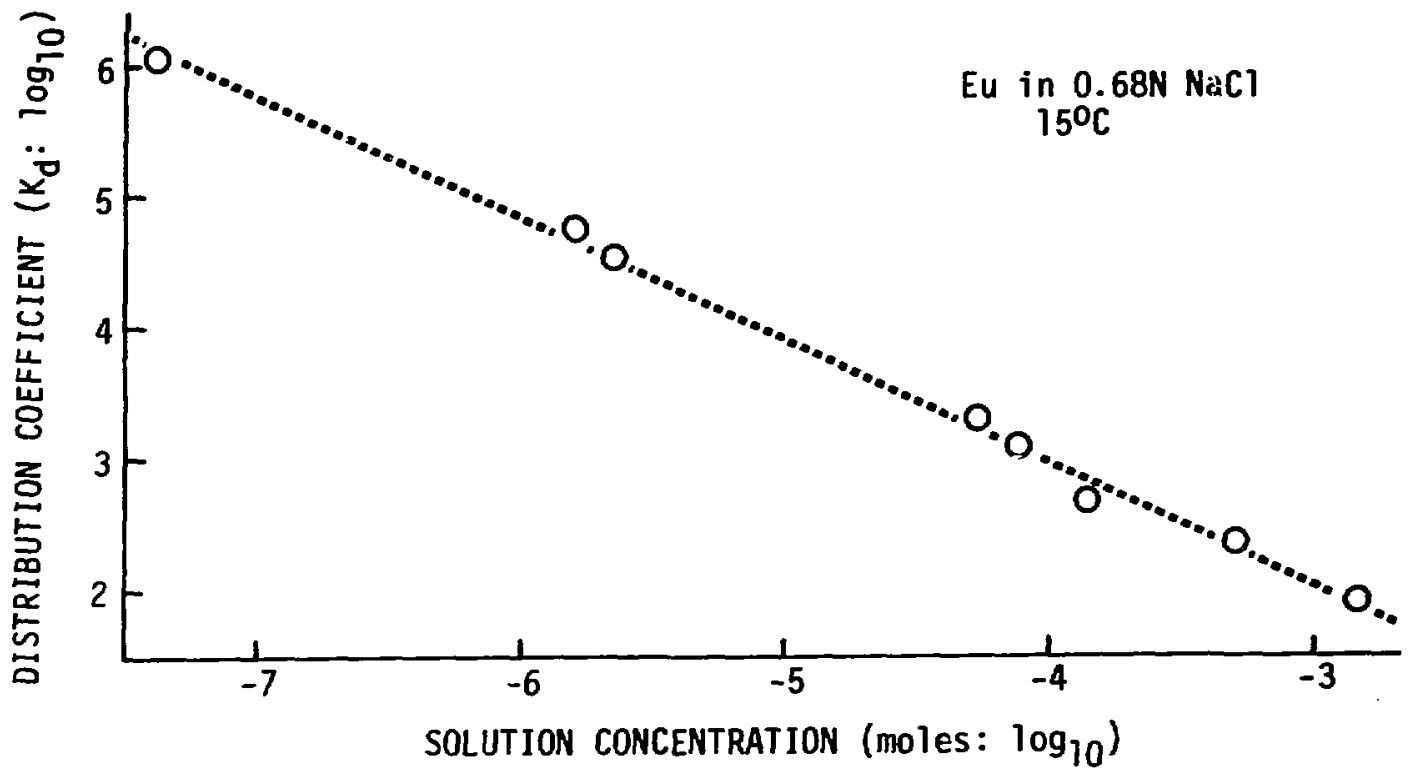

Figure 1. Typical concentration dependence of $K_{d}$ for a central North Pacific deepsea, smectite-rich clay. In this case, $d(\log \mathrm{Kd}) / \mathrm{d}(\log$ Eu concentration $)=-0.93$.

a distribution coefficient of 1000 (on the low side of the published range), its characteristic diffusion time through a 30-meter layer of deep-sea clay is increased from 100,000 to 100 million years. The possibility of such long barrier time constants is one of the key factors that focused the attention of the Seabed Program on the sediment layer rather than on underlying basalts of the deep seabed.

The number of variables affecting the diffusion/sorption of ions from dissolving spent fuel or high-level waste in a saturated deep-sea clay are enormous. They include ion concentrations, ionic speciation, complexing, oxidation states, competitive ion effects, and sorption kinetics. Rather than attempt to resoive all possible combinations of these factors, we are addressing most of them in single-ion systems, with a few complex mixtures and a series of laboratory columri diffusion experiments to be followed by in situ experiments to determine whether our models accurately reflect real diffusion rates.

\section{Perturbed Environment}

Explicit knowledge of the influence of a thermally hot source of ions on effective diffusion rates is not yet available. We know that the rate of pure molecular diffusion increases with increasing temperature. However, the effect of this trend is counteracted by an increase in distribution coefficients with increasing temperature (Fig. 2). Further experimental data and model development are required to generate a realistic picture of diffusional ion transport around a hot waste cannister. The problem is compounded by the fact that temperatures in excess of $100^{\circ} \mathrm{C}$ 
DISTRIBUTION COEFFICIENT ( $\left.K_{d}: \log _{10}\right)$
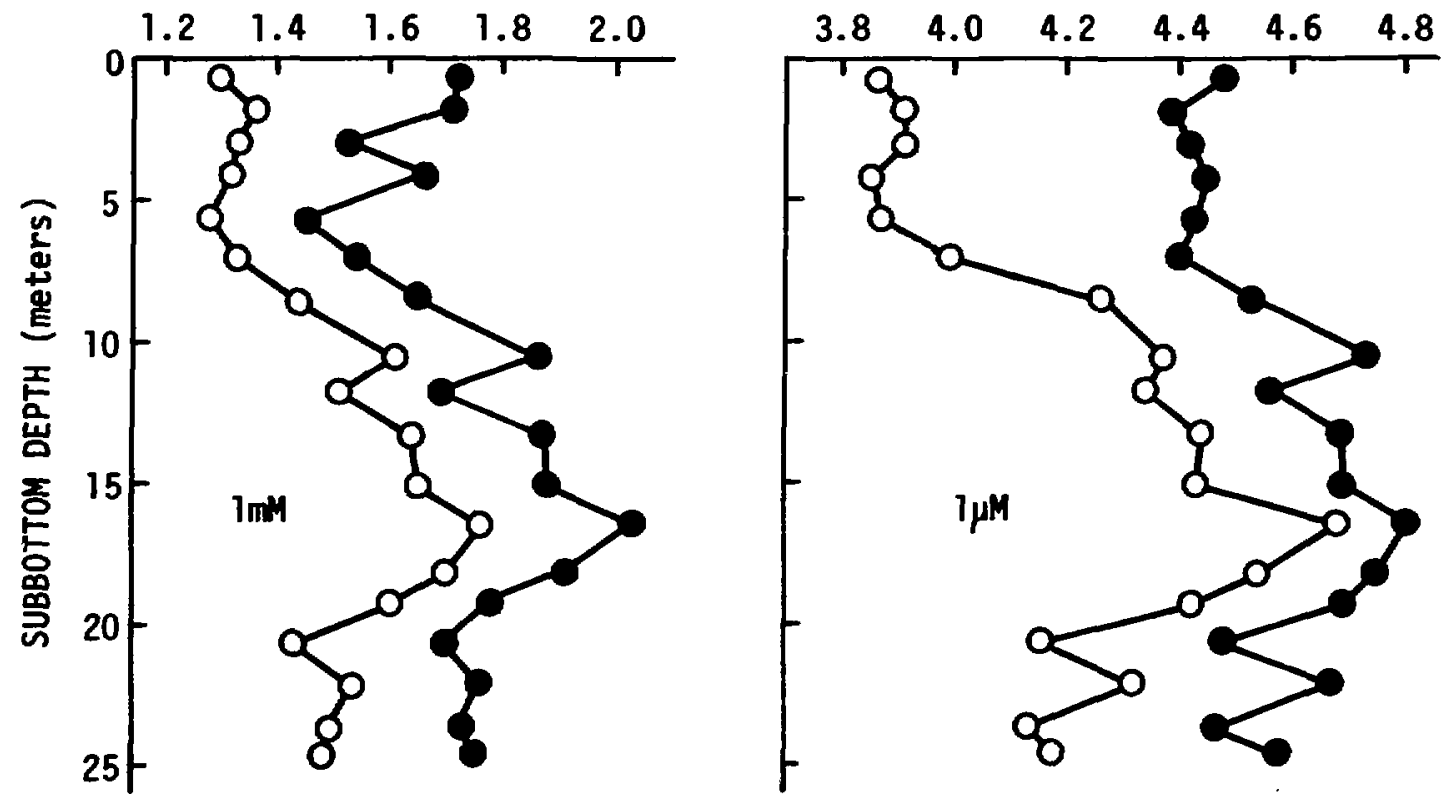

Figure 2. Distribution coefficients for 1 millimolar and 1 micromolar Eu in $0.68 \mathrm{~N}$ $\mathrm{NaCl}$ relative to a profile of North Pacific sediments (core LL44-GPC3, $33^{\circ} 19.9^{\prime} \mathrm{N}$, $\left.157^{0} 49.4^{\prime} \mathrm{W}\right)$. Open circles $-15^{\circ} \mathrm{C}$ experiments, filled circles - $85^{\circ} \mathrm{C}$ experiments. These data show: (I) the variability in $K_{d}$ values to be expected in mid-ocean deepsea clays; (2) the temperature dependence of $K_{d}$ values (a $70^{\circ} \mathrm{C}$ temperature rise roughly doubles $K_{d}$ for most sediments); and (3) the very marked concentration dependence of $K_{d}$ values (given roughly by $K_{d}=$ (Eu concentration) ${ }^{-0.9}$ ).

will hydrothermally metamorphose the natural deep-sea suite of fine grained clay minerals and ferromanganese oxyhydroxides and likely will change their sorptive properties. In addition the $\mathrm{pH}$ of pore waters is buffered only weakly by the carbonate bicarbonate system, and their Eh is poised only weakly by the presence of a small amount of dissoived oxygen. Thus, the dissolving waste may alter the pH-Eh regime in its immediate vicinity and again change sediment sorptive properties in ways that could be difficult to predict.

\section{DISCUSSION AND CONCLUSIONS}

Our initial assessment of the ability of deep-sea clays to contain nuclear waste is optimistic. Yet we have no delusions about the complexity of the natural geochemical system and the perturbations that may result from emplacement of thermally-hot waste cannisters. Even though we may never be able to predict the exact nature of all these perturbations, containment of the nuclides by the waste form/ cannister system until most of the heat has decayed, and burial of the waste to a 
sufficient depth that the altered zone can be treated as a "black box" source of dissolved nuclides to the enclosing "unperturbed" sediment, encourage us to believe that ion migration in the deep seabed can be modeled accurately and that our preliminary estimates of migration rates are likely to be reasonably realistic.

\section{REFERENCES}

Hickox, C. E., Jr., 1977, Steady thermal convection at low Rayleigh number from concentrated sources in porous media. Sandia Laboratories, Albuquerque, Rept. SAND 77-1529, 48pp.

McDuff, R. E. and Gieskes, J.M., 1976, Calcium and magnesium profiles in DSDP interstitial waters : diffusion or reaction? Earth Planet. Sci. Letters, vol 33, no 1 , ppl-10. 
PHYSICAL AND BIOLOGICAL TRANSPORT*

\author{
Mel G. Marietta \\ Sandia Laboratories ${ }^{+}$ \\ Albuquerque, New Mexico 87185
}

\begin{abstract}
In order to evaluate the feasibility of sub-seabed waste disposal, it is necessary to consider the resu'ts cf leakage or accidental failure to emplace the canister within the deep-sea sediments. Such accidental release is possible for any waste disposal option, and the associated risks must be evaluated so that comparisons between options can be made. Therefore, one must be able to trace the migration of escaped radionuclides from the canister site within the sediments (or possibly elsewhere for various accident events), through the sediments, water column, and ecosystem to man. Only in this way can the environmental impact of sub-seabed nuclear waste disposal be quantitatively evaluated.

A mathematical model which describes this migration of radionuclides through the various transport mechanisms of the sea must be written in order to quantify the release of a given amount of waste material. This model is directed towards answering two questions. What is the effect upon the marine environment, and what is the effect upon man? These questions require a predictive capability for the levels of radioactivity in the marine biota and for the dose to man.
\end{abstract}

*This work was supported by the U. S. Department of Energy under Contract AT(29-1)-789.

${ }^{\dagger}$ A U. S. Department of Energy Facilitg. 
The model must be made up of several modules: the near field transport with heat effects, far-field transport in the sediments, water column and biological transport, human dosimetry, affected human populations, and finally human health effects. The resultant human health effects will answer the question concerning the effect on man. The concentrations of radioactivity predicted in the water column and biological transport module will provide part of the answer for the question concerning ecosystem effects. The complete answer requires a knowledge of how a given concentration of radioactivity will effect a particular organism. This knowledge will be gained through an investigation of the radiosensitivity of deep-sea organisms. The topic of this talk is the vater colum and biological transport module, and this effort can be broken down into three parts: the modeling, data acquisition, and radiosensitivity studies. ill of these activities are inter-related, and the entire effort requires an investigative team of diverse backgrounds.

The current radionuclide migration module must use the output from the far-field ion transport module as input. The boundary which is the spatial interface between the two models is a horizontal plane located beneath the lower limit of biological activity in the sediments. The water column and biological transport module must then follow the migration of radionuclides through the upper few centimeters of the sediment, the water colum, and the biological material in both the sediments and water. It must include both horizontal and vertical dispersion. Man acts as a predator only in the upper part of the water column.

The deep-sea ecosystem is very diverse in the number of species present. The benthic boundary layer is populated by a species-rich microbiota and a highly mobile, opportunistically feeding megafauna. It has been observed that the population numbers of this megafauna decrease with increasing depth so that the standing crops may be as much as two orders of magnitude lower on the abyssal plain than on the continental shelf. Metabolic rates are generally low. Oxygen consumption may also be two orders of magnitude lower. Growth rates, reproductive ratea, mortality, and recolonization are believed to be much lower although there is still insufficient evidesce to support these beliefs.

From these few observations, it is apparent that modeling the transport through a species-web is an exceedingly complex task. Fortunately, a simpler approach is possible. Accordingly, the ecosystem has been compartmentalized into a few compartments. A compartment represents a funch ional grouping of many species of the biota. The species within a compartment are believed to behave similarly in both their inter-relationships with their environment and the way that they pass along radionuclides. Group bounds on the standing crop and metabolic rates may then be assigned to each compartment by observing the constituents of the group. For example, in the benthic boundary layer the biological compartments might be the infauna, epibenthic fauna, and migrating animals. 
The mass transports between biological compartments and physical compartments are most complex. Besides predator-prey relationships, the radionuclides may be transported by excretion, mortality, adsorption, migration and molting. In addition, both organic and inorganic sediments and/or particulate materials may be consumed. Radionuclides may also be taken up directly from the water column and/or interstitial water. There are various physicas transports to be considered such as association-disassociation in the sediments and water column for both organic and inorganic matter, erosion-sedimentation, vertical and lorizontal water dispersion, bioturbation, horizontal migration of benthic megafauna, vertical migration of mid-water animals, and the dispersion of host particulate matter.

A complete radionuclide migration model independent of population dynamics and biomass spatial variations (patchiness) which includes these phenomena consists of the equation of state of seawater and of the conservation equations of mass, momentum, energy, combined specific density of dissolved salts, particulate burden, and concentration of radioactivity for each compartment in the system. Then, given a geometrical boundary of the system (basin) to be examined, a description of the various surface and body forces, and a knowledge of the distribution of the state variables (velocity, temperature, salinity, density, pressure, concentration of radicactivity per compartment, concentration of particulates) at an initial time, the distribution of the state variables at fucure times can be found by a forward integration in time. Unfortunately, the equations are non-linear and contain a variety of phenomena which are applicable to many different circumstances of fluid flow. It is not desirable to solve the entire system including all the pehnomena which occur in the ocean. Therefore, the so-called filtering approximation of global ocean forecasting will be used to suppress some of the phenomena by an appropriate averaging process in space and/or time. This is also a necessary step because of the difficulty in describing the initial state of the sea.

Such a modeling effort is an evolutionary process. The ocean must be examined and a real model idealized from it. This real model is the compartmentalized web along with the parameters that are believed to be sufficient to describe the included transport phenomena. The mathematical model is an abstraction of the real model from which quantitative predictions can be made. The development of techniques for measuring biological parameters has been a part of the seabed p igram for several years.

In the deep-sea, such data acquisition is a challenging problem. Specimens must be captured and brought to the surface under pressuie. Metabolic rates should be measured in situ if possible. Attempts at amswering these biological problems are using some old and some new techniques. Investigations of the benthic boundary layer microbiota, meiofauna, and megafauna standing crops using box corers and tag and recapture techniques are being carried out by $R$. Hessler (Scripps). Measurements of metabolic rates of bacteria and amphipods returned to the laboratory and maintained in pressurized vessels are being performed by A. Yayanos (Scripps). 
Investigations into the standing crops of the euphotic and mid-water zones using towed nets has been handled by J. McGowan (Scripps). The development of several capture techniques including a 300 meter free vehicle collection net, a free vehicle abyssopelagic population monitor, and the development of techniques to measure the metabolic rates of organisms in situ including a free vehicle grab respirometer and in situ invertebrate and fish trap respirometers are being performed by $\mathrm{K}$. $\mathrm{L}$. Smith (Scripps).

The physical oceanographic investigations are just starting under the guidance of A. R. Robinson (Harvard), R. Bryan (Princeton), and P. Rhines (Woods Hole Oceanographic Institute). In addition the radiochemistry work involving the particulate selectivity, particle burden in the water column, and the initial radionuclide concentrations due to fallout is being done by $V$. Bowen (Woods Hole Oceanographic Institute). Each iteration of the modeling process must be cycled through the entire group to insure that the important tie with the real ocean is maintained.

In addition, the radiosensitivity work must be completed in a parallel fashion with the data acquisition and modeling. Because of the difficulty in catching and maintaining deep-sea organisms, techniques must be developed on shallow water organisms. Then, the data points obtainable from a few deep-sea animals can be compared with shallow water curves (for example $L_{50}$ 's) in order to identify possible variations in radiosensitivity between similar deep and shallow water species. A better understanding of the radiosensitivity of deep-sea organisms will allow the environmental effect of the compartmental radioactivity levels predicted by the model to be realistically evaluated.

The parallel activities of data acquisition, radiosensitivity investigations, and modeling while paying careful attention to filtering out unimportant ocean phenomena with increasing length and time scales will provide the final. tool in the process of assessing environmental feasibility of sub-seabed nuclear waste disposal. 
MECHANICAL RESPONSE OF MARINE SEDIMENTS RESULTING

FROM ISOLATION OF RADIOACTIVE WASTES*

\author{
Paul R. Dawson \\ Sandia Laboratories, ${ }^{\dagger}$ Albuquerque, NM 87185
}

Introduction

The mechanical response of marine sediments must be evaluated under a wide range of conditions to properly assess the feasibility of isolating radioactive wastes in the seabed. Analyses are required, for example, to determine if a competent barrier is reformed after emplacement of wastes and to ensure that the barrier is not breached as a result of long-term creep. The capability of analytical tools to accurately predict sediment mechanical response must first be determined and, if need be, improved to include essential physical phenomena.

Saturated marine sediments are complex two-constituent systems consisting of a porous skeleton and seawater pore fluid. If loads are applied sufficiently fast to the sediment-water system, deformations occur before the fluid can move through the skeleton to relieve excess pore pressures. In contrast, when loads are applied slowly, fluid movement relative to the skeleton dissipates pore pressures and leaves the skeleton to carry the load. Frequently in the analyses of sediment-water systems under conditions that approach one of these limiting cases, singleconstituent models are used in conjunction with material properties determined from tests with the appropriate drainage to approximate the sediment response. It must be recognized that the internal stress distribution within the system can be quite different from the average stresses predicted

*This article is sponsored by the U.S. Department of Energy, Division of Environmental Control Technology, under Contract AT(29-1)-789.

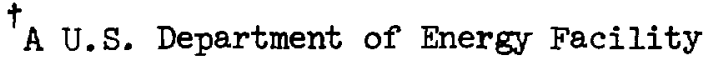


by using a single-constituent model. However, single-constituent models provide a reasonable starting point in the development of predictive capability for marine sediment systems near the limiting cases. This approach $\mathrm{h}=\mathrm{s}$ been adopted in the Seabed Disposal Program for dynamic analyses of penetrometers (one concept for waste emplacement) and for long-term stability of canister-sediment systems.

This paper concentrates on the preliminary analyses associated with long-term stability of marine sediments subjected to thermally induced density gradients. The manner in which the results impact laboratory testing for creep characteristics of marine sediments is presented. Finally, the basis of a numerical method that incorporated a two-constituent sedimentwater model is discussed.

\section{Long-Term Canister-Sediment Stability}

A heat producing canister emplaced in the seabed causes surrounding sediments to increase in temperature. The thermal expansion that results from the temperature rise creates density gradient.s in the sediment and, thus, produces differential body forces. These differential body forces could potentially induce creeping motion of the sediment similar to a convective cell in a fluid medium. The upward motion of the sediment might then drag the canister upward and lead to a breach in the isolation of the wastes.

The possibility of thermally induced density gradients driving creep movement of saturated marine sediments has been analyzed using a thermomechanically coupled finite element code for creeping viscoplastic flow and conductive-convective heat transfer [1]. The system analyzed consists of a heat producing canister buried at a $30 \mathrm{~m}$ depth in a sediment column $100 \mathrm{~m}$ thick. The canister generates heat at an initial rate of $3.5 \mathrm{~kW}$ and with a nominal half-life of 30 years. The canister and sediment velocities are required to be equal at their interface. Further, the sediment skeleton structure is assumed to reform following emplacement so that the disturbance occurring as a result of emplacement can be neglected. The initial temperature of the sediment is defined as $280 \mathrm{~K}$ and the sediment is initially at rest. Other boundary conditions are depicted in Figure 1.

The viscoplastic flow formulation is based on Iamb's variational principle. The Euler equations resulting from this variational principle, including an added incompressibility constraint, are summarized as follows:

Equilibrium:

$$
\sigma_{i j, j}+x_{i}=0
$$

Strain rate:

$$
\dot{\varepsilon}_{i j}=\left(u_{i, j}+u_{j, i}\right) / 2
$$

Incompressibility:

$$
\dot{\varepsilon}_{i i}=0
$$


Boundary conditions:

$$
\begin{array}{ll}
\text { Boundary conditions: } & u_{i}=\bar{u}_{i} \text { on } s_{u} \\
& \sigma_{i j} \nu_{j}=\bar{T}_{i} \text { on } s_{T} \\
\text { initial conditions: } & u_{i}=\hat{u}_{i} \text { in } v
\end{array}
$$

where $\sigma_{i j}$ is the stress tensor; $X_{i}$ is the body force vector; $\epsilon_{i j}$ is the strain tensor; $u_{i}$ is the velocity vector; $\bar{u}_{i}$ is an imposed velocity on the subset $S_{\mathfrak{u}}$ of the total surface; $\bar{T}_{\mathfrak{i}}$ is an imposed traction vector the subset $\mathrm{ST}$ of the total on surface; $\nu_{i}$ is the unit normal vector to $S_{T}$ and $\hat{u}_{i}$ is the initial velocity vector in the region $\mathrm{V}$. The body forces, $\mathrm{X}_{\mathrm{i}}$, are dependent on the temperature and can be represented as

$$
x_{i}=\rho g_{i}\left(1-\alpha\left(\theta-\theta_{\text {ref }}\right)\right)
$$

where $\rho$ is the density; $g_{i}$ is the gravitational vector; $\alpha$ is the expansiveity; $\theta$ is the temperature; $\theta_{\text {ref }}$ is the reference (initial) temperature.

The constitutive equation used to characterize the creep behavior of the sediments is an isotropic relationship between the deviatoric stresses and strain rates. Parameters for the creep constitutive equation, appropriate specifically for saturated deep ocean sediments, are not yet lnown. In order to perform the preliminary analyses discussed herein, creep data for fine-grained clays, reported in the literature $[2,3,4,5]$, were used to construct a constitutive equation $[6]$. This constitutive equation is $a$ linear relationship between stress and strain rate:

$$
\sigma_{\Pi}^{\prime}=1.7 \times 10^{-10}[\exp (146866 / \theta)] \dot{\varepsilon}_{\Pi}
$$

where of! is the effective deviatoric stress ( $\mathrm{Pa}$ ); $\dot{\epsilon}_{\Pi}$ is the effective strain rate $\left(s^{-1}\right)$; and $\theta$ has units of degrees Kelvin. The reported data indicate that the relationship between stress and strain rate is actually nonlinear. However, the limited data available were used to formulate a constitutive equation appropriate for the low stress levels expected. Whether or not the strong dependence in Equation (7) is realistic will be determined from the creep testing program initiated for deep ocean sediments. Further, the initial elastic strength is neglected in Equation (7).

Several assumptions are incorporated in this formulation. One is that inertia can be neglected in the equilibrium equations. A second assumption is that strain increments resulting from the creep of sediment are much larger than elastic strain increments. The third assumption is that changes

*The deviatoric stress tensor is defined by $\sigma_{i j}^{\prime}=\sigma_{i j}-\frac{1}{3} \delta_{i j} \sigma_{\mathrm{kk}}$. The effective deviatoric stress is a scalar defined by $\sigma_{\Pi}^{\prime}=\left(\frac{3}{2} \sigma_{i j}^{\prime} \sigma_{i j}^{\prime}\right)^{\frac{1}{2}}$ and the effective strain rate is given by $\varepsilon_{\Pi}=\left(\frac{2}{3} \dot{\varepsilon}_{i j} \dot{\epsilon}_{i j}\right)^{\frac{1}{2}}$. 
in dersity resulting from thermal expansion affect only the body forces in the equilibrium equations. The density changes are arsumed to have negligible effect on the continuity and energy equations. The fourth assumption is that pore water within the sediment skeleton has adequate time to drain so that excess pore-pressures do not occur.

The energy of the system is modeled using a formulation for conductiveconvective heat transfer. The governing equations for heat transfer are as follows:

$$
\begin{aligned}
& \text { Energy: } \quad\left(k \theta_{i_{i}}\right),,_{i}-\rho \mathrm{c}_{p} u_{i}{ },_{i}+Q=\rho \mathrm{C}_{p} \dot{\theta} \\
& \text { Boundary conditions: } \quad \theta=\bar{\theta} \text { on } s_{\theta} \\
& \bar{q}=\left(k \theta_{i}-\rho c_{p} u_{i} \theta\right) u_{i} \text { on } s_{q} \\
& \text { Initial conditions: } \quad \theta\left(x_{i}, 0\right)=\bar{\theta}\left(x_{i}\right)
\end{aligned}
$$

where $\mathrm{k} i \mathrm{i}$ the conductivity; $C_{p}$ is the specific heat; $Q$ is the heat generation rate; $\bar{q}$ is the surface heat flux on $\mathrm{s}_{\mathrm{q}}$; $\bar{\theta}$ is the imposed temperature on $S_{\theta}$; and ${ }^{\prime} i$ is the unit normal vector to $S_{q}$.

An incremental solution procedure has been used to follow the histories of the coupled heat transfer and creep deformations [I]. The analyses begin by determining the velocity distribution using the equations grverning viscoplastic flow with the material properties and body forces based on sediment at ambient conditions (i.e., ambient temperature and hydrostatic stress state determined by overburden load). The temperature distribution corresponding to the end of the first time step is then determined by solving the energy equation using a Crank-Nicholson $1 \perp$ nite difference algorithm in the time domain. The system geometry is then advanced to its new position corresponding to the end of the time step through Euler integration of tine velocity field. Subsequent movement of the sediment-canister system is evaluated by continuing to step the solution ahead in time and using the velocities and temperatures at the end of one time step as initial conditions for the next step.

The thermomechanical response of the axisymmetric canister-sediment system has been analyzed for a period of approximately 25 years following emplacement. The velocity history shown in Figure 2 for the canister indicates that the velocity increases at an increasing rate for times less thar 5 years. Between approximately 5 and 15 years after emplacement, the canister velocity increases, but at a decreasing rate. The peak canister velocity of approximately $3 \mathrm{~nm} / \mathrm{s}$ occurs at approximately 15 years after emplacement and:subsequeritly diminishes. The peak temperature at the canister-sediment interface, however, peaks at the much earlier time of between 3 and 4 years. This apparent lag in the mechanical response relative to the thermal response results from the buoyant motion of the sediment depending on the spatial distribution of energy rather tran solely peak temperatures. That is, movement of sediment due to buoyancy depends both 
on the amount of sediment that has experienced a temperature rise as well as the thermal gradients within the sediment.

The predicted strain rates and effective deviatoric stresses have been examined to assess if the constitutive equation based on low stress Ievels was appropriate in the canister motion analyses. The deviatoric stresses for four points at various distances away from the canister centerline (on a line rinning horizontally through the canister miaheight) have jeen plotted in Figure 3 with the corresponding temperatures for these points shown in Figure 4. The temperature of points nearer the canister climb fastest and begin to decay the earliest. At approximately $3 \mathrm{~m}$ from the canister, the maximum temperature rises approximately $93 \mathrm{~K}$ after approximately 8 years. At Ereater distances from the source, the maximum teinperature rise is less and vccurs at later times.

The strain rates for the four points increase with time as the region heats and the buoyant forces increase. The magritude of the strain rates are in proportion to the distance from the canister. The effective deviatoric stresses, however, demonstrate a quite different behavior. At a radius of $3.094 \mathrm{~m}$, tne effective deviatoric stress diminishes quite rapidly as the temperature rises and the viscosity $\left(\mu=\sigma_{\Pi}^{\prime} / \dot{\epsilon}_{\Pi}\right.$ from Equation $\left.(7)\right)$ decreases. At large radii ( $\mathrm{r}=10.719$ or $17.5 \mathrm{~m})$, the temperature rise is much less $(\angle \theta \leqslant 10 \mathrm{~K})$ and the effective deviatoric stresses are roughly in proportion to the strain rates (viscosity remaining relatively constant). However, at the radius of $7.031 \mathrm{~m}$ the effertive deviatoric stresses increase only until sigrificant heating begins after 2 to 3 years. The stresses then level off as the decrease in viscosity with increased temperature is offset by the increase in buoyancy of the heated region. Stresses begin to increase for radii of $3.094 \mathrm{~m}$ and $7.031 \mathrm{~m}$ as the temperature rise begins to decay and the viscosity increases.

The magnitude of the stresses indicated in Figure 3 for the four points in the sediment are less than $1 \mathrm{kPa}$. Thus, the assumption that low stress differences relative to the yield stress $(\sim 20 \mathrm{kPa})$ is valid. Experimental observations [2] indicate creep rates eventually diminish to nero for stress differences in this low stress regime. This implies that the effective viscosity would increase with time instead of the constant relationship used in these analyses and that motion of the canister would be expected to cerse. A more accurate assessment of the magnitude of the motion requires that creep parameters for marine sediments, appropriate at stress levels indicated by these analyses, be determined.

Two-Constituent Models

In the preliminary modeling of sedimert creep, single-constituent behavior was assumed because the deformation is sufficiently slow to allow dissipation of excess pore water. However, a two-constituent model is required if the interaction of the skeleton and fluid during heating and subsequent creep are to be assessed. Current development of numerical capability that includes a two-constituent model is based on a variational statement for the rate of work of the system. The variational statement includes the rate of work in deforming the skeleton and pore water, the rate of work by traction vectors over the surface and by body forces, and the rate of work 
by the fluid on the skeleton (and vice versa) due to their relative motion. To this variational statement, has been added a constraint condition representing conservation of mass of the skeleton and pore fluid.

Conclusions

Preliminary analyses of canister movement resulting from thermally induced density gradients have been performed using a creeping viscoplastic flow model in conjunction with a creep equation evaluated from literature data for fine-grained clay. The stress levels predicted are quite low relative to the sediment quasi-static strength indicating that creep testing of marine sediments at very low stress is necessary.

\section{REFERENCES}

1. P. R. Dawson and P. F. Chavez, "COUPLEFLO - A Computer Code for Coupled Creeping Viscous Flow and Conductive-Convective Heat Transfer, Part I. Theoretical Background," Sandia Laboratories, SAND-78-1406, Hovemiter, 1978.

2. A. W. Bishop and H. T. Lovenbury, "Creep Characteristics of Two Undisturbeó Clays," Proceedings of the 7 th Int. Conf. on Soil Mech., Mexico 1, pp. 29-37, 1969.

3. K. Akai, T. Adachi, and N. Ando, "Existence of a Unique Stress-StrainTime Pelation of Clays," Soils and Foundations, Jap. Society of Soil Mechanics and Foundation Fngineering, Vol. 15, No. 1, March 1975.

4. A. Singh and J. K. Mitchell, "General Stress-Strain-Time Functions for Soils," J. of Soil Mech. and Foundations Division, ASCE, SMI, pp. 2146, Jan. 1968.

5. J. K. Mitchell, R. G. Campenella, and A. Singh, "Soil Creep as a Rate Process," J. of Soil Mech. and Foundations Division, ASCE, SMl, pp. 231-253, Jan. 1968.

6. P. R. Dawson, "Bouyant Movement of Nuclear waste Canisters in Marine Sediments," SAND-78-0941, July, 1978. 


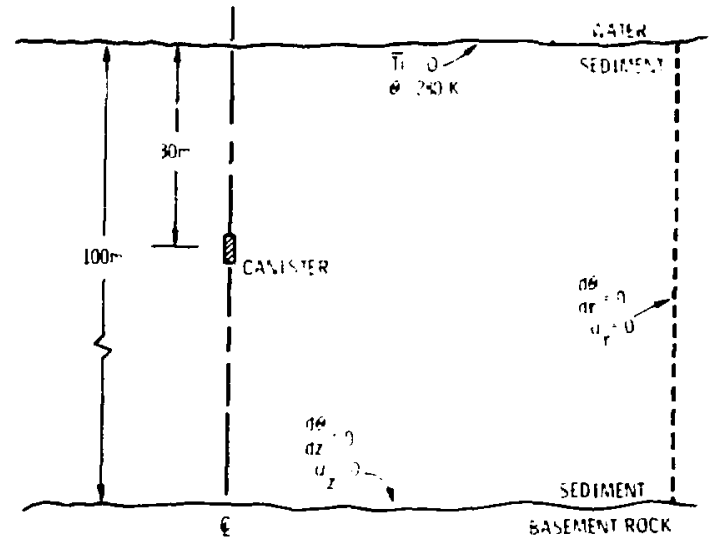

Figure 1. Axisymmetric Sediment-Canister Model

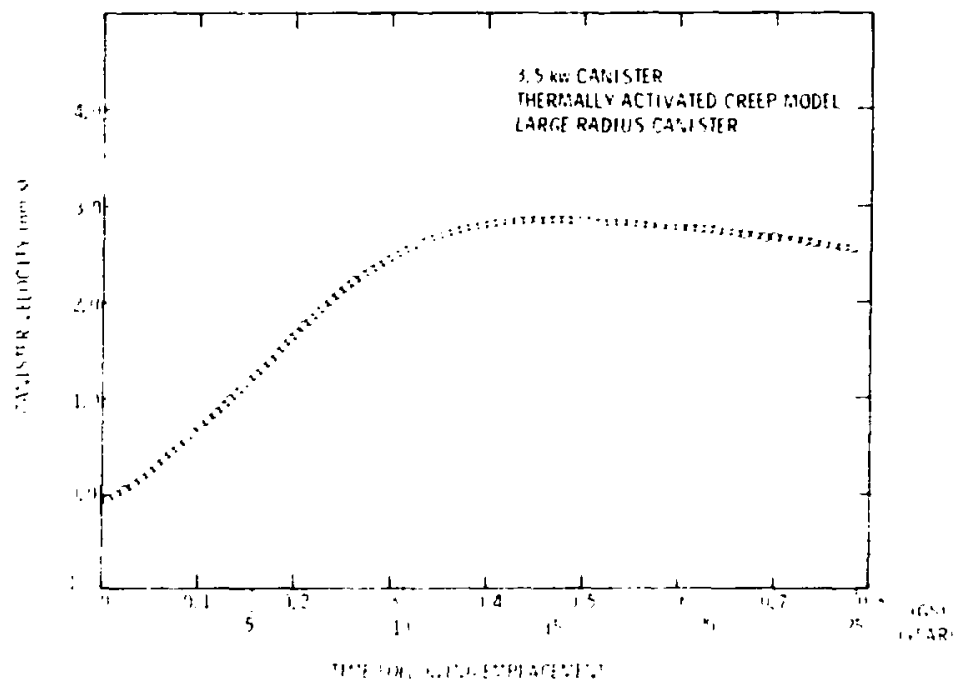

Figure 2. Canister Velocity History 


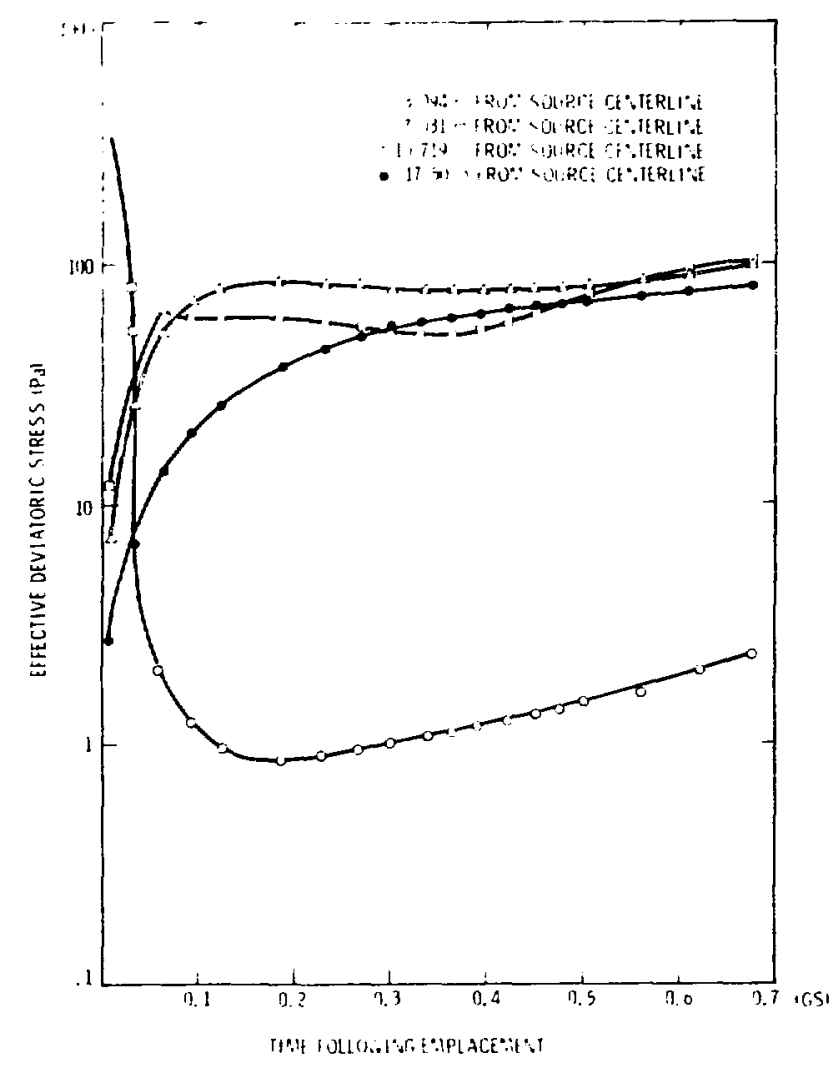

Figure 3. Sediment

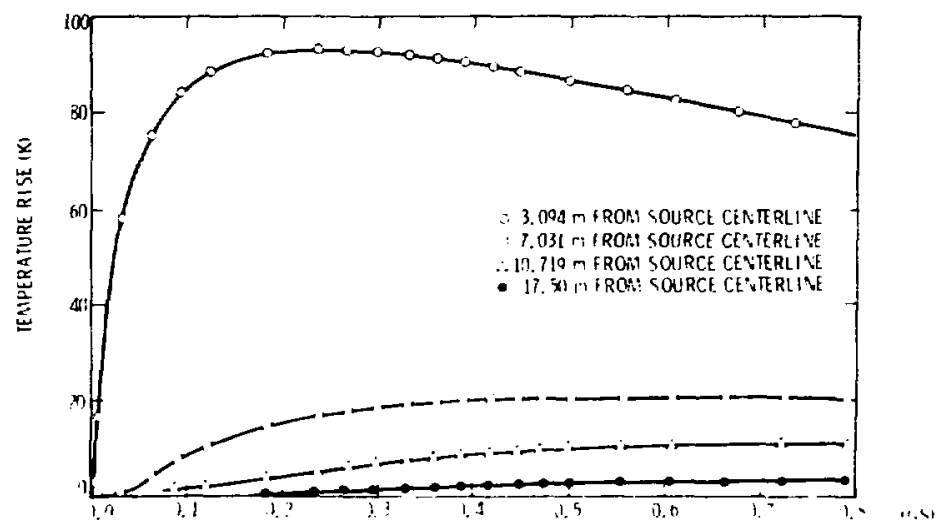

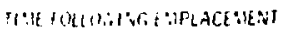

Figure 4. Sediment Thermal Response 


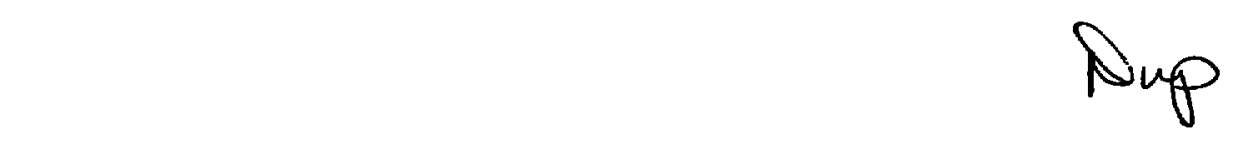

\title{
GEOLOGICAL DISPOSAL INVESTIGATIONS IN GRANITE \\ AT THE NEVADA TEST SITE *
}

\author{
L. B. Ballou \\ Lawrence Livermore Laboratory \\ Livermore, California
}

\section{INTRODUCTION}

The Lawrence Livermore Laboratory (LLL) has participated in the Nevada Nuclear Waste Storage Project since early 1977, under the programmatic direction of the Nevada Operations Office (NV) of the Department of Energy (DOE). The major LLL effort in the project is in the design, execution, and analysis of in-situ field tests in the granitic intrusive known as the Climax stock. This stock, located near the northeast corner of the Nevada Test Site, was the site of two nuclear weapons effects tests in the $1960^{\circ} \mathrm{s}$. An available vertical shaft access to a horizontal drift complex at a depth of $420 \mathrm{~m}$ below the surface remained from these tests.

A set of thermal properties tests and permeability tests were conducted in the existing underground workings in FY1978. A retrievable geologic storage test of spent fuel assemblies was authorized in 1978 and is currently in the construction and procurement phase with initial loading of spent fuel scheduled for the spring of 1980. A set of rock mechanics tests, designed to generically evaluate the potential of a hard crystalline rock mass as a host medium for geologic storage/disposal of reactor wastes has been proposed. This proposal is in the conceptual reviev phase and is not currently funded.

Prfmarfly due to fts proximfty to ongoing nuclear weapons test areas, the Climax site has been determined to be avallable for generic tests such as those mentioned above, but not avaflable for consideration as a long term waste repository site. Therefore, the in-situ testing program at this site is generic in character, but is providing valuable insights into the response of the medium to the loads lmposed by emplacement of both simulated and actual waste materials.

* Work performed under the ausplces of the U. S. Department of Energy by the Lawrence Livermore Laboratory under contract number $\mathrm{H}-7405-\mathrm{ENG}-48$. 
The Climax stock is a composite granitic intrusive body located near the northeast corner of the NTS. It has been the subject of fairly extensive geologic exploration in support of past nuclear test activities. It is named for the Climax mine which is located in Paleozoic rocks north of the granitic outcrop. The stock outcrops over an area of about $4 \mathrm{~km}^{2}$. Geophysical evidence suggests that the stock expands conically with depth. It is bounded on the surface by faults to the east and west.

The two main units in the stock, granodiorite and quartz monzonite, contain the same minerals as granite but in different proportions. The LLL tests are being conducted in the quartz monzonite unit. The graln size in both units is about 1 to $4 \mathrm{~mm}$, but the quartz monzonite contains scattered feldspar crystals up to 50 mum in diameter. The test level is above the regional water table and unsaturated. About 1 to 2 percent water is localized in fractures and pores and is free to migrate unfer thermal or pressure gradients.

The stock contains numerous fractures aid local faults. Relatively unfractured and unfaulted areas have been Identified for locating the test arrays. The physical properties of the Climax stock rocks are similar to those measured in granites elsewhere; therefore, the results from these tests should be applicable to a generic evaluation of granitic rocks as a medium for storage of reactor wastes.

The layout of the excavation at the $420 \mathrm{~m}$ depth is shown in Figure 1.

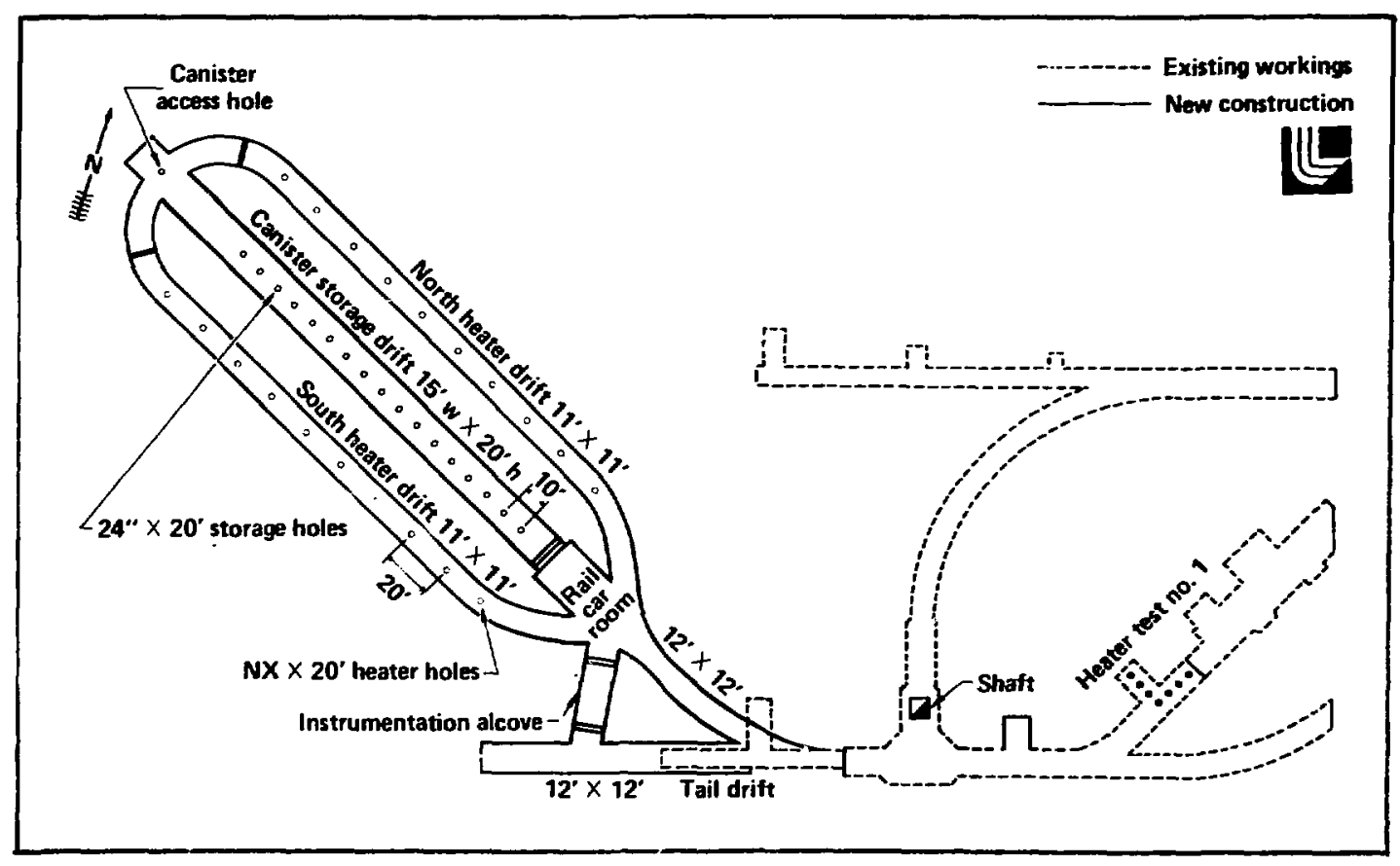

Figure 1. Plan of $420 \mathrm{~m}$ depth level in Climax stock, NTS, showing layout and location of heater tests and spent fuel test. 
THERMAL PROPERTIES TESTS

During the five month period from October, 1977, to March, 1978, two tests were conducted to evaluate the in-situ thermal properties of the granite. The tests ut11ized an L-shaped array of $18 \mathrm{AX}(48 \mathrm{~mm})$ and $\mathrm{NX}(76 \mathrm{~mm})$ diamond cored vertical holes drilled in the floor to a depth of 9 to $12 \mathrm{~m}$. The array was oriented parallel and perpendicuiar to the principal vertical fracture direction. Two $19 \mathrm{~mm}$ diameter $3 \mathrm{~m}$ long, $5 \mathrm{~kW}$ electrical resistance heaters were installed in holes near the ends of the array, and a total of 60 sheathed thermocouples were installed in the other holes. The mid-plane of the instrumentation was located $7.5 \mathrm{~m}$ below the drift floor; a depth of $425 \mathrm{~m}$ below the ground surface. All holes were backfilled with vermiculite ins.ulation from the top of the instrument array to the drift floor.

The tests were operated at various power levels and time durations which were selected to achieve a constant average power of $3.7 \mathrm{~kW}$. In both tests refluxing of small quantities of water - probably circulating fluid lost to the fracture system during drilling operations .- was noted. This refluxing produced a distortion of the thermal field, with slightly higher than anticipated temperatures observed above the midplane of the array.

The conclusion of the two test sequences is that the thermal conductivity at the experimental site is essentially isotropic and only slightly temperature dependent over the range of temperatures investigated. The peak rock temperature was approximately $350^{\circ} \mathrm{C}$. The thermal conductivity derived from the data is $3.0 \mathrm{w} / \mathrm{m}-\mathrm{K}$, about $157 \mathrm{higher}$ than the mean value of laboratory measurements without confining pressure. The derived thermal diffusivity is $1.2 \mathrm{~mm}^{2} / \mathrm{sec}$ and is in good agreement with laboratory measurements on fintact core samples.

\section{PERMEABILITY TESTS}

Following the thermal tests the borehole instrumentation in the proximity of one heater was reconfigured to conduct a set of in-situ permeability tests at elevated temperatures. The instrumentation included inflatable borehole packers, pressure transducers and thermocouples. Remotely-operated valves provided the capability to operate the system from the surface. This test series was operated for about three months and included a total of seven pressurization test cycles, six of which yielded interpretable results. These tests, which utilized compressed air as a working fluld, required approximately 100 hours to produce sufficient pressure decay to assure reliable data. During this period, particuiar care to control the heater power was needed to minimize temperature variations in the boreholes.

The deduced permeabilities are extremely low - all less than 1 nanodarcy. The permeability consfstently declines as the temperature increnses and rises agatn upon coolfng. The fn-situ test data are consistent with laboratory measurements made on other granitic rocks and confirm that although the Climax granite is fractured, it is a very impermeable medium.

\section{SPENT FUEL TEST}

The concept of a retrievable geologic storage test utilizing spent fuel assemblies in the Climax stock has evolved over the past 2-1/2 years. The test which was authorized $1 \mathrm{n} 1978$ and is now being constructed is designed to take advantage of two existing facilities at the NTS in order to minimize the cost and time necessary to implement the test. 
The existing vertical shaft and mining support facilities at the rilmax site, which were refurbished to support the heater test described earlier, were readily available for the construction of a new test array. The new excavation has been designed to simulate the geometry of a typical hard rock repository element.

The other facility at NTS which will support this test is the Engine - Maintenance Assembly and Disassembly (E-MAD) factlity, which is equipped to receive, remotely encapsulate, and provide interim storage of fuel assemblies.

The plan for this test includes the acquisition, characterization, encapsulation, transportation, emplacement, storage and retrieval of about 12 spent PWR fuel assemblies. The fuel assemblies will be placed into storage at a power level of about $2 \mathrm{~kW}$ per assembly, which occurs when this fuel is about 2-1/2 years out of core. A storage duration of 3 to 5 years is planned. Electrical simulators which are identical in geometry and power output will also be emplaced in the storage array in order to identify any significant differences in response of the medium to the presence of ionizing radiation in addition to the thermal sources.

The canister storage drift is located between two parallel drifts where electrical heaters will be located. They will be operated with power histories to impose thermal effects on the storage drift and adjacent pillars equivalent to those which would occur from a large repository array. Temperature, displacement, and stress instrumentation will be distributed in the test array to measure the response of the medium to the imposed loads.

Construction of the underground test complex is in progress as well as design and procurement of specialized fuel canister handling equipment. The fuel assemblies will be emplaced in storage within the next year.

\section{ROCK MECHANICS TESTS}

In the course of the field testing activities in the climax stock, it has become increasingly apparent that some aspects of the existing rock mechanics computational and experimental capabilities are not adequate to predict the long term effects of $1 \mathrm{~m}-$ posed thermal loads on fractured hard crystalline rock musses. This is particularly true in the context of optimizing repository designs for maximum confidence in precluding release of hazardous wastes to the biosphere at an economically acceptable cost. Specific problem areas include

- Limitations in sensitivity and time and temperature stability of existing rock mechanics measurement equipment which is usable in a field test environment.

- Limitations in existing rock mechanics computational schemes in the explicit treatment of discontinuities in the medium (fractures, joints, shear zones, etc.).

LLL has proposed a series of tests and supporting development activities to improve the ability to project the results of in-situ tests into the repository design phase. In particular, overdriven tests which lead to exceeding established failure criterla will be valuable in establishing the engineering safety factors which are associated with candidate repository designs in hard crystalline rocks.

\section{NOTICE}

"This report was prepared as an account of work sponsored by the United States Government. Neither the United States nor the United States Department of Energy, nor any of their employees, nor any of their contractors, subcontractors, or their employees, makes any warsanty, express or implied, or assumes any legal liability or responsibility for the accuracy, completeness or usefulness of any information. apparatus, produc or nrocess discloced or renrecents that its lle 
WASTE DISPOSAL IN GRANITE: PRELIMINARY RESULTS

FROM STRIPA, SWEDEN

\author{
Neville G. W. Cook ${ }^{*}$, John E. Gale ${ }^{\star \star}$ and Paul A. Witherspoon ${ }^{+}$ \\ ${ }^{*}$ Department of Materials Science and Mineral Engineering \\ University of California, Berkeley 94720 \\ **Department of Earth Sciences, University of Waterloo \\ Waterloo, Ontario, Canada \\ +Department of Earth Sciences, Lawrence Berkeley Laboratory and \\ Department of Materials Science and Mineral Engineering \\ University of California, Berkeley 94720
}

\title{
INTRODUCTION
}

Significant quantities of nuclear wastes exist already and continue to be produced (U.S. DOE, 1978). To provide better protection for man and the environment from the potential hazard posed by these wastes than does the present practice of near surface storage, disposal by deep burial in suitable geologic sites is favored (NRC, 1957; IRG, 1978).

The principal attraction of deep geologic disposal is that it provides a practicable method for isolating these wastes physically from the biosphere for long periods of time. The principal uncertainty about deep geologic disposal concerns the rate at which toxic components of the wastes may leak back into the biopshere.

There are two major aspects to the design of a suitable underground repository for nuclear wastes, namely, the intrinsic properties of the geologic media, and the effects which the excavation of a repository, emplacing radioactive waste in it and, finally, sealing the excavations will have on the isolation of these wastes. The evaluation of these aspects involves concepts familiar to most mechanical engineers. The extent to which this is not true arises from geologic terminology and the inherent variability and uncertainty of the properties of sub-surface media.

Although there are some places where an underground repository could be sited above the present water table, it cannot be assumed that climatic or other changes will not alter this condition during the period over which isolation of wastes is required. Accordingly, it must be assumed that the repository and rock mass will become saturated after the excavations have been sealed.

The porosity and permeability of intact specimens of granite are of the order of one percent and $10^{-21}$ meters $\mathrm{s}^{2}\left(10^{-14} \mathrm{~m} / \mathrm{sec}\right)$, respectively. It may seem that these and the ratio of permeability to porosity are such that the time taken for ground- 
water contaminated with radioactive materials from the waste to move 1 kilometer to surface from the repository would be about $30 \mathrm{million}$ years, even for a highly adverse hydraulic gradient of unity. Unfortunately, the continuity of most hard rock, including granite, is interrupted by sets of tensile fractures, known as joints, and shear fractures resulting from tectonic and thermal stresses to which they have been subjected in geologic history. The hydraulic permeability of such rock masses is dominated by the flow of water through these discontinuities.

The changes in temperatures of the nuclear waste and of the geologic media around it, resulting from the radioactive decay of the waste, are fundamental to the design and performance of an underground repository.

The purpose of this paper is to examine the questions of the permeability and thermomechanical response of a granitic rock mass in the light of preliminary results from field experiments being conducted in a defunct mine some $340 \mathrm{~m}$ below surface at Stripa, situated about 200 kilometers west-north-west of Stockholm, Sweden (Witherspoon and Degerman, 1978).

\section{GEOHYDROLOGIC MEASUREMENTS}

The flow of groundwater through geologic discontinuities has been likened to laminar fluid flow between closely spaced parallel plates (Huitt, 1956; Snow, 1968 ). Using this analogy, the volume rate of flow per unit width of the discontinuity measured nomal to the direction of flow is given by:

$$
q=\frac{(2 b)^{3}}{12 \mu} \rho g i \text {, }
$$

where $q=$ the volume rate of flow per unit width of the discontinuity measured normal to the direction of the flow $\left(\mathrm{m}^{3} / \mathrm{m} . \mathrm{s}\right)$;

$(2 b)=$ the aperture of the fracture $(\mathrm{m})$;

$\rho=$ the density of water $\left(\mathrm{kg} / \mathrm{m}^{3}\right)$;

$g=$ the gravitational acceleration $\left(9.81 \mathrm{~m} / \mathrm{s}^{2}\right)$;

$i=$ the hydraulic gradient $(\mathrm{m} / \mathrm{m})$, and

$\mu=$ the dynamic viscosity of water $(\mathrm{kg} / \mathrm{m} . \mathrm{s})$.

Discontinuities in a rock mass are seldom orientated randomly; generally they occur in sets of three or more preferred orientations with a degree of statistical distribution about these directions. The apertures of discontinuities have been found to follow approximately a log-nomal distribution (Snow, 1970) and, obviously, the aperture decreases with increasing compressive stress across the discontinuity.

To evaluate the permeability of a rock mass containing such discontinuities, it is necessary to determine their orientations, the spacing between discontinuities, and the distribution and magnitude of their apertures. This can be done in part by mapping of the discontinuities exposed on the walls of underground excavations and surface outcrops; measurements of discontinuities in core recovered from holes diamond drilled in the rock mass from surface and underground; optical surveys of the walls of these boreholes and, finally, the analysis of the results of hydraulic tests conducted in lengths of boreholes and tunnels. A11 of these approaches are being used at Stripa.

Figure 1 is a plan of the site showing the location of the principal boreholes for geohydrologic measurements. There are three boreholes from surface, SBH1, 2, and 3,15 subsurface boreholes, and a length of tunnel. 


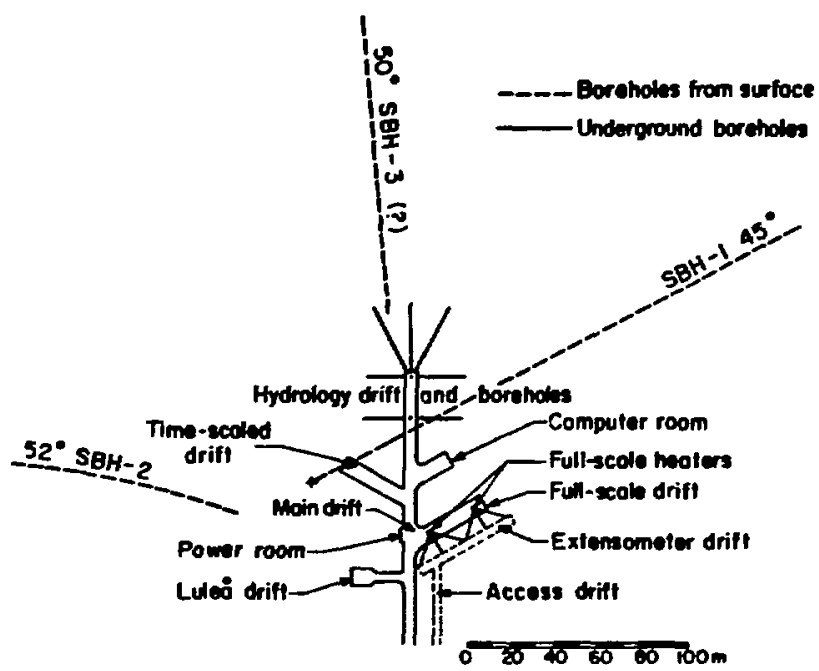

Fig. 1. A plan of the test site at Stripa showing the timescale and full-scale drifts and the extensometer drift for the latter, which is located at a lower elevation, as well as other drifts and boreholes.

In addition to visual observations of discontinuities, the hydrologic properties of the rock mass are being evaluated by analyzing the results of pressure measurements made in lengths of each borehole shut off for test purposes by packers, and by measurements of the water pressure distributions around, and the rate of water flow into, the test drift (Gale and Witherspoon, 1978).

\section{THERMOMECHANICAL MEASUREMENTS}

The rate at which heat is released by spent fuel from light water reactors and by reprocessed high level waste from such reactors, decays more rapidly than time to the power $-1 / 2$, so that for dissipation of the heat into the rock mass, even by thermal conduction in one dimension only, the temperature of an underground repository must reach some peak value and then diminish (Cook and Witherspoon, 1978).

The average peak temperature of a planar repository is proportional to the initial power loading density of the repository. The diffusion of heat by conduction causes the temperature in the rock above and below such a repository to increase with time. These changes in temperature have significant mechanical and hydrological consequences for the performance of a repository.

Mechanically, the changes in temperature result in themally induced compressive stresses within the heated zone of the rock mass and induced tensile stresses outside this zone. The latter stresses may increase the apertures of discontinuities in this zone by decreasing the value of the normal compressive stress across them.

Hydrologically, the enhanced permeability resulting from such increases in aperture, together with increased bouyancy and decreased viscosity of the groundwater as a result of increases in its temperature, may accelerate the transport of groundwater from the repository to the biosphere. These effects will have to be evaluated in the design of any nuclear waste repository.

In addition to the increase in the average temperature of a repository, the temperature of each canister of waste must increase, establishing a temperature gradient away from it to allow for the dissipation of the heat released as a result of radioactive decay within the canister by conduction into the rock around it. This temperature gradient induces compressive stresses parallel to the walls of holes containing 
canisters, which could result in decrepitation of the rock (Cook, 1977; St. John, 1978). Such decrepitation could decrease the thermal conductivity of the rock leading to unacceptable temperatures of the waste, or it may result in mechanical damage to the canisters and their contents.

The magnitude and characteristics of these thermomechanical effects can be estimated by calculating conductive temperature fields and the resulting thermally induced stresses and displacements. However, the results of such calculations depend upon the values used for the mechanical and thermal properties of the rock. In general, few of these properties have been measured and most have been obtained on intact specimens of rock in laboratory tests (Clark, 1966). The in situ properties of a rock mass containing discontinuities can be expected to differ significantly from those of intact 1aboratory specimens. The motivation for conducting heating experiments underground, using electrical heaters to simulate the thermal effects of canisters of radioactive wastes, is to obtain values for the thermomechanical properties of such a rock mass, and data with which to validate repository designs.

The near field thermal and mechanical effects, both in the short-term and in the long-term, can be studied using full-scale electrical heaters to simulate the heat released by the radioactive decay of waste in canisters. The interaction between adjacent canisters, which would occur in the long-term and result in an increase in the average temperature of a repository, can be simulated in the near field by increasing the temperature around a heater with a number of peripheral heaters (8) at a suitable radius $(0.9 \mathrm{~m})$ from the main heater and extending over a greater axial length $(4.3 \mathrm{~m})$ than that of the main heater $(2.5 \mathrm{~m})$.

As it is not practicable to study the far field, long-term effects, even for the period of a few decades needed to reach peak temperatures, before the need for such data arises, a time-scaled heater experiment can be used to study sone of these aspects. Time and 1 inear dimensions occur in solutions to all problems of heat conduction in solids in the form $k t / x^{2}$, where $k$ is the thermal diffusivity, $t$ is time and $x$ is a linear dimension (Carslaw and Jaeger, 1959). This relationship has been used in the time-scaled experiment to accelerate time by an order of magnitude through a reduction in linear dimensions to a little less than a third of full size.

Using a finite element code to allow for the geometrical complexities introduced by the underground excavations and Tinear thermo-elasticity with values for the properties of the granite as measured in laboratory tests, the thermal fields (Chan et al., 1978a) and induced displacements and stress (Chan et al., 1978b) have been predicted as a function of time for the two heating experiments at Stripa. To date the methodology of the experiment has been to compare predicted and measured values of temperature, displacement and stress as a function of time, with the purpose of identifying disparities between the measured behavior of the rock mass in situ and predictions based on linearity and the properties of intact specimens of rock.

Some examples of comparisons between measured and predicted values of temperatures and displacenients are illustrated in Figures 2 through 4 . It appears linear heat conduction accounts well for changes in temperature even though the rock mass is discontinuous. However, measured displacements are consistently between 1/4 and $1 / 2$ the predicted values, despite the fact that, theoretically, they should be a function only of the temperature field, the boundary conditions and a factor $D$ given by:

$$
D=\frac{1+v}{1-v} \alpha \text {, }
$$

where $v=$ Poisson's ratio, and

$\alpha=$ the coefficient of 1 inear thermal expansion 


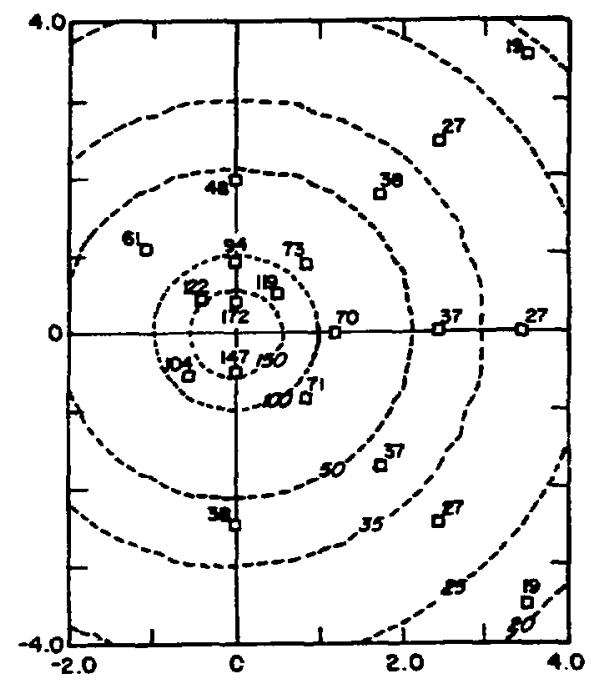

Fig. 2. Predicted isotherms and measured temperatures in a horizontal plane through the middle of the $5 \mathrm{~kW}$ fullscale heater, 150 days after heating had started. (Scaie for both $x$ and $y$ axes is given in meters.)

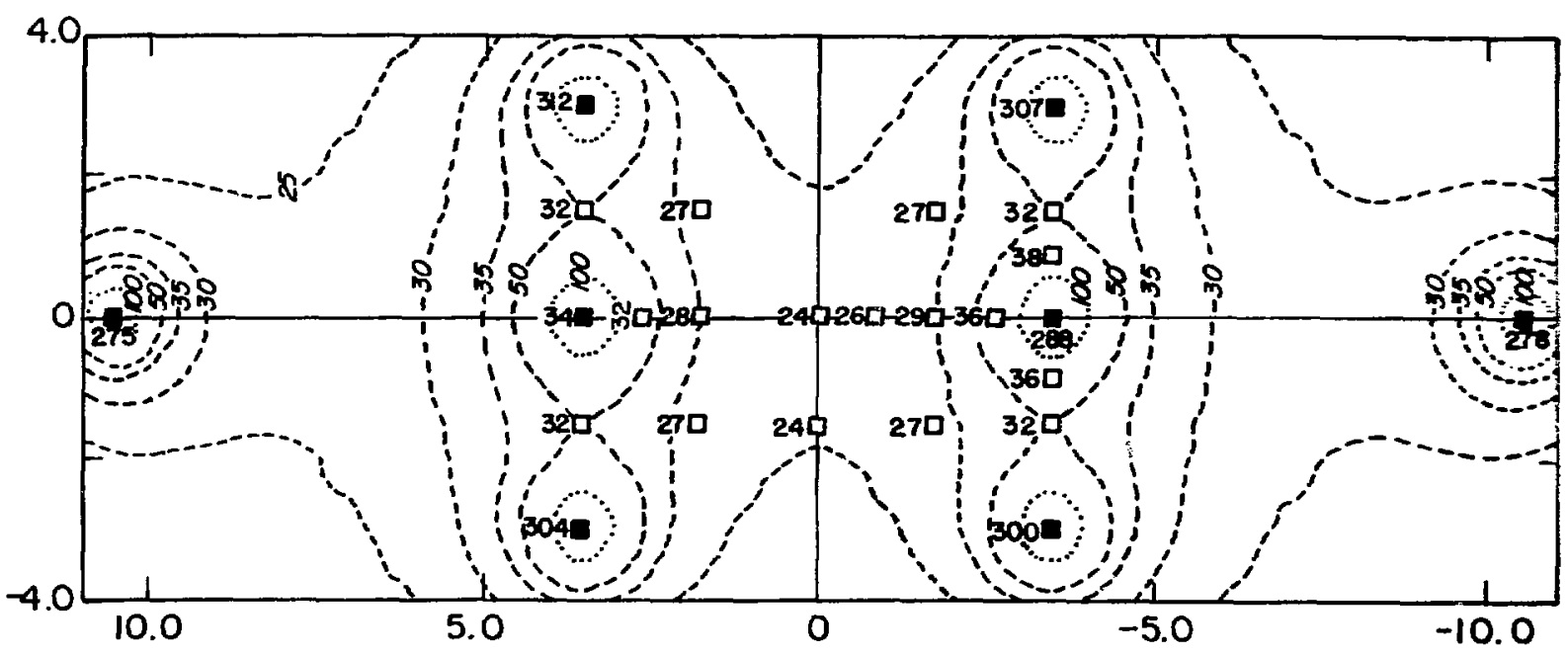

Fig. 3. Predicted isotherms and measured temperatures in a horizontai plane through the middle of the time-scale experiment 190 days after heating had started. (Scale for both $x$ and $y$ axes is given in meters.) (Squares marked in black indicate temperatures at heater locations.)

An analysis of the ratio between measured and predicted values of dispiacement as a function of time, that is, increasing temperature and displacement in the rock is shown for a number of measurements in Figure 5 . This analysis suggests that the rock mass is behaving in a non-linear manner, as would be expected from the presence of discontinuities, and that the value of $D$ for the rock mass is less than that deduced from laboratory tests.

Thermally induced stresses should be a function only of the temperature field, the boundary conditions and a factor $S$ given by:

$$
S=\frac{\alpha E}{1-v}
$$



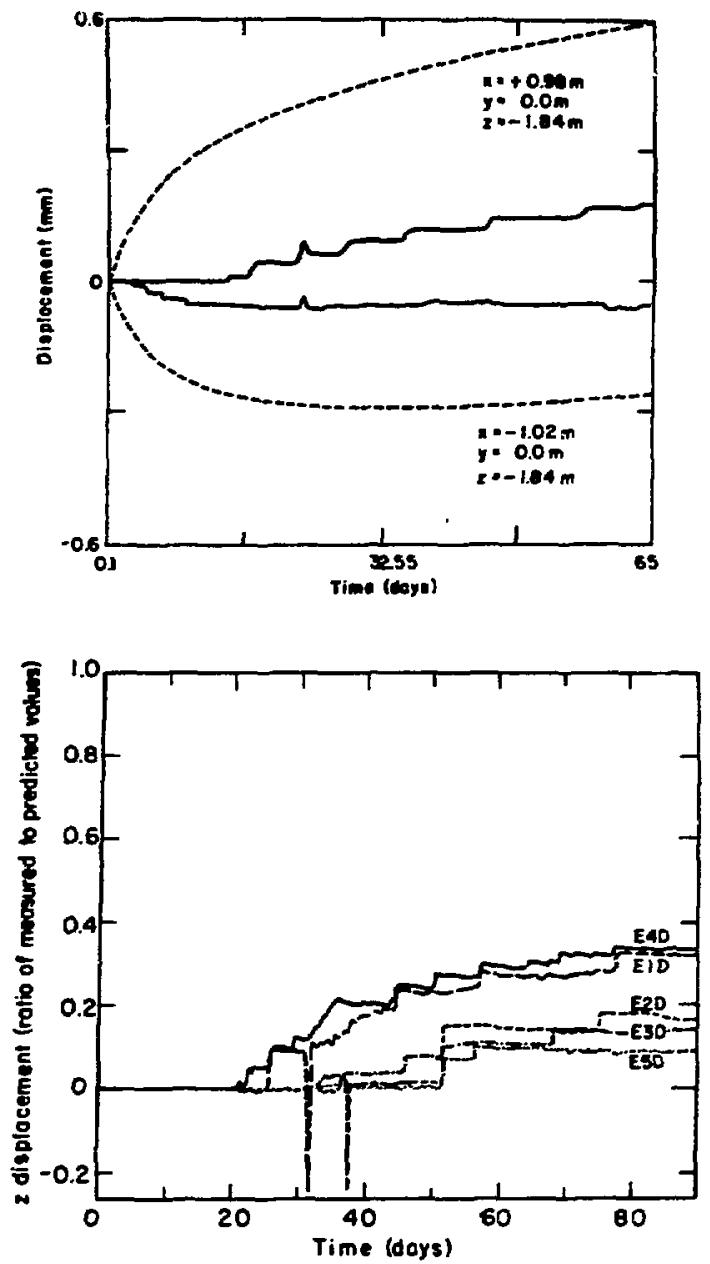

Fig. 4. Predicted (dashed) and measured (solid) horizontal dispiacements below the $5 \mathrm{~kW}$ full-scale heater at anchor points symmetrically positioned on each side of the heater. Both of these displacements are measured relative to the collar of the hole on the wall of the extensometer drift.
Fig. 5. The ratio between measured and predicted values of displacement for anchor points situated $3 \mathrm{~m}$ above and below the mid-plane of the time-scaled heaters as a function of time for each of the 5 extensometers. [The $x-$ and $y$-coordinates are EID $(0,0)$, E2D $(0,1.75)$; E3D $(0,2.62)$; E4D $(-1.5 ; 0)$, and $\operatorname{EDD}(1.5,-1.75)$ cf. Fig 3.]

where $E=$ Young's modulus, and the other terms are as defined above.

As usual it has proved difficult to make accurate stress measurements, and calibration of the total stress measuring system has not proved to be completely satisfactory yet, as it has been for temperature and displacement. Accordingly, although the measured values of stress appear to compare well with the predicted values, it would be premature to draw conclusions from these data at this stage.

\section{CONCLUSION}

The results of this experiment to date indicate that the temperature fields in a rock mass containing geologic discontinuities can be predicted with accuracy using the simple linear theory of heat conduction.

Geologic discontinuities appear to introduce significant non-linear thermomechanical behavior into the rock mass as a result of which the thermally induced displacements are much less than those predicted by the simple theory of thermoelasticity, using laboratory values for Poisson's ratio and the coefficient of thermal expansion.

The additional compliance introduced into the rock mass by geologic discontinuitie affects the thermally induced stresses but to a liesser degree than the displacements. 
Further analytical, laboratory and field studies are expected to resolve many of the current uncertainties, especially field data gathered during a planned cooling down period following the switching off of the heaters scheduled in the near future.

\section{ACKNOWLEDGEMENT}

This work was prepared under the auspices of the U. S. Department of Energy working in collaboration with the Swedish Nuclear Fuel Supply Company.

\section{REFERENCES}

Carslaw, H. S. and J. C. Jaeger (1959). Conduction of Heat in Solids, 2nd ed. Oxford, Clarendon Press.

Chan, T., N. G. W. Cook and C-F. Tsang (1978a). "Theoretical Temperature Fields for Heater Project at Stripa", LBL 7082, Lawrence Berkeley Laboratory, University of California, Berkeley.

Chan, T. and N. G. W. Cook (1978b). "Calculated Thermally Induced Displacements and Stresses for Stripa Heater Experiments", LBL 7061, Lawrence Berkeley Laboratory, University of California, Berkeley.

Clark, S. P., Jr. (ed) (1966). Handbook of Physical Constants, The Geological Society of America, Inc.. iew York, Memoir 97.

Cook, N. G. W. (1977). "An Appraisal of Hard Rock for Potential Underground Repositories of Radioactive Wastes" LBL 7004, UC-70, Lawrence Berkeley Laboratory, University of California, Berkeley.

Cook, N. $\therefore$. W. and P. A. Witherspoon (1978). "In Situ Heating Experiments in Hard Kock: Their Objectives and Design", OECD Seminar on In-Situ Heating Experimients in Geological Formations, Stripa, Sweden, September 12-15.

Gale, J. E. and P. A. Witherspoon (1978). "An Approach to the Fracture Hydrology at Stripa: Preliminary Results", OECD Seminar on In-Situ Heating Experiments in Geological Formations, Stripa, Sweden, September 12-15.

Huitt, J. L. (1956). "Fluid Flow in Simulated Fracture", Journal American Inst. Chemical Eng., Vol. 2, pp. 259-264.

Interagency Review Group (IRG) on Nuclear Waste Management, (1978). "Report to the President", TID-28817 (draft), Washington, D. C.

National Research Council (1957). "The Disposal of Radioactive Waste on Land", Committee or Waste Disposal, Division of Earth Sciences, Washington, D. C. National Academy of Sciences.

St. John, C. M. (1978). "Computer Models and the Design of Underground Radioactive Waste Repositories prepared for special Summer Session "Current Developments in Rock Engineering", Massachusetts Institute of Technology, June 26-30.

Snow, D. T. (1968). "Rock Fracture Spacings, Openings and Porosities" Journal of Soil Mechanics and Foundations Division, ASCE, SM1, January, pp. $7 \overline{3}-91$. 
Snow, D. T. (1970). "The Frequency and Apertures of Fractures in Rock", J. Rock Mech. Min. Sci., Vol. 7, pp. 23-40.

U. S. Department of Energy (1978). "Report of Task Force for Review of Nuclear Waste Management", DOE/ER-0004/D, UC-70, Washington, D. C., U. S. Department of Energy, Directorate of Energy Research, February.

Witherspoon, P. A. and 0. Degerman (1978). "Swedish-American Cooperative Program on Radioastive Waste Storage in Mined Caverns Program Summary", LBL 7049, Lawrence Berkeley Laboratory, University of California, Berkeley. 
EVALUATION OF BASALT FLOWS AS

A WASTE ISOLATION MEDIUM

\author{
R. A. Deju
}

Rockwell Hanford Operations

Richland, Washington 99352

In February 1976, the U. S. Energy Research and Development Administration (currently the U. S. Department of Energy) expanded the commercial radioactive waste management programs and established the National Waste Terminal Storage Program. Its mission was to provide multiple facilities in various deep geologic formations within the United States. The Office of Waste Isolation was estabiished within the Union Carbide Corporation - Nuclear Division to provide program management of the National waste Terminal Storage Program. The overall program consisted of investigating a number of geologic rock types to determirie their suitability for terminal storage of radioactive waste. Basalts, such as the Columbia Plateau basalts, which underlie a large portion of the Pacific Northwest and the Hanford Site, were selected for initial geologic reconnaissance. Atlantic Richfield Hanford Company was asked in May 1976, by the Office of Waste Isolation, to plan and execute a basalt feasibility study. Geologic exploration of Columbia Plateau basalts was needed to determine the feasibility of utilizing those formations as a site for terminal storage of commercial nuclear waste.

In September 1977, the National Waste Terminal Storage Program was restructured. While emphasis was still on a salt repository, additional funds were given to support investigations of two U. S. Department of Energy sites - Hanford and Nevada. The Hanford Program is presently the responsibility of the U. S. Department of Energy Richland Operations Office. Rockwell Hanford Operations (successor to Atlantic Richfield Hanford Company) is the prime contractor responsible for this work. The Basalt Waste Isolation Program within Rockwell Hanford Operatiojs has been chartered with the responsibility of conducting these investigations. This program is divided into systems integration, geology, hydrology, engineered barriers studies, engineering testing, and the construction of a near-surface test facility. 


\section{SYSTEMS INTEGRATION}

The systems integration program has involved the definition of studies required as part of the qualification of basalt as a repository medium for nuclear waste storage. Trese studies include the planning of demonstration facilities as well as the specifying of scientific studies to be undertaken during and for the licensing process.

\section{GEOLOGIC STUDIES}

Studies to date have been broken up into two categories: reconnaissance regional studies and local studies of a more intensive nature within the Pasco Basin of southcentral Washington State. As part of the regional studies, a survey of published and unpublished documents concerning the geology of the Columbia Plateau was completed. Over 1,500 references were cataloged and listed. In addition, mapping of the basalt within the Columbia Plateau and the overlying Late Cenozoic sediments have been conducted. The stratigraphic nomenclature of the Columbia River Basalt Group has been revised by the U. S. Geological Survey and is presently being compiled.

The Pasco Basin studies during fiscal year 1978 have included a definition of the local stratigraphy of the basalt and an assessment of the viability of using chemical properties and magnetic characteristics for stratigraphic definition. In addition, extensive mapping has been conducted and continues to be conducted in structurally significant areas of the basin.

\section{HYDROLOGIC STUDIES}

The hydrologic program provides hydrologic criteria and evaluation techniques by which potential repository sites can be selected and evaluated. During fiscal year 1978, as part of the regional studies, a bibliographic search of information on the regional hydrology of the Columbia Plateau was completed. The Pasco Basin studies were scoped to determine, in key areas, specific parameters that would allow modeling of this basin. As part of the Pasco Basin studies, a geohydrologic annotated bibliography was completed. These hydrology studies required the drilling of several holes. As-builts and core hole histories of individual holes were prepared after completion of each hole. All drilling and testing activities to date indicate that the basalts are present in a predictable pattern beneath the basin. Formation depths, thicknesses, and hydrologic properties are consistent with previous estimates based on earlier data.

\section{ENGINEERED BARRIERS}

The emplacement of nuclear waste in a geologic repository can cause physicochemical perturbations to the surrounding environment. The engineered barriers program attempts to identify from a physicochemical standpoint the features of various barriers to transport of radioactive contaminants. The program looks at four potential barriers: the waste, the rock, the container, and the overpack. In addition, 
a borehole plugging system is analyzed as a final barrier once the repository is sealed and abandoned. To assess the effectiveness of such a multiple barrier system, one examines chemical changes which could lead to chemical reactions, both at the canister (phase transformations, dissolution) and outside the repository (dissolution) precipitation, and sorption/desorption).

\section{ENGINEERING TESTING}

The engineering testing program is conducting those tests required to define engineering characteristics of basalt needed for conceptual engineering design studies and qualification of basalt as a storage medium for a nuclear waste repository. Engineering testing began with a literature review of laboratory and field studies on the engineering properties of basalt.

In addition, laboratory studies and an in situ demonstration program are being coordinated. The latter will further examine the behavior of an entire basalt rock mass composed of rooms embedded in the central portion of a basalt flow.

\section{THE NEAR-SURFACE TEST FACILITY \\ DESIGN AND CONSTRUCTION}

During the early phase of the Basalt Waste Isolation Program, the need for in situ thermal and mechanical testing of basalt was identified. This need of engineering data, to qualify basalt as an acceptable repository medium and to provide design information, could be met by construction of an in situ test facility. Detailed planning was initiated in October 1977. Construction began in June 1978, and the first test is scheduled for startup in early 1980. 
58 


\title{
GENERIC ASPECTS OF SALT REPOSITORIES
}

\author{
R. B. Laughon \\ Battelle Memorial Institute, Project Management Division \\ office of Nuclear Waste Isolation
}

The study of geologic disposal of radioactive wastes in salt was precipitated in 1957 when a panel of the National Academy of Sciences-National Research Council (NAS-NRC), acting on a request by the Atomic Energy Commission (AEC), suggested burial in bedded salt deposits as the best of the many methods that it had considered. Shortly after that recommendation work began by prime contractors to the AEC to evaluate such a disposal method.

Early work was concentrated in the Kansas portion of the Permian Basin and climaxed in an underground vault test in an abandoned salt mine at Lyons, Kansas, in the late $1960^{\prime} \mathrm{s}$. In that test, simulated waste was placed in the salt in an instrumented test to confirm waste handling procedures and to measure the physical and chemical response of the salt to the thermal load imparted on the rock formation by this simulated waste. The concept of using a similar Kansas mine for an actual waste repository was abandoned when the potential affect of nearby solution mining activities could not adequately be resolved.

Following a inatus of a few years, when the emphasis of the waste management program was directed toward temporary storage in surface facilities, the evaluation of bedded salts of the Permian Basin was resumed in southeastern New Mexico. That work is presently culminating in the Haste Isolation Pilot Plant concept, which will be thoroughly discussed in papers that follow.

Advantages cited by the NAS-NRC in either their original recommendation or in subsequent confirmations of that recommendation are as follows:

1. Salt beds are abundant; loss of salt resources would be negligible.

2. Salt is an effective natural shield against gamma radiation.

3. The natural plásticity of salt at the temperatures imposed by the waste will effectively seal the waste in the host rock. 
4. Plastic flow of the salt will relieve stress conditions produced by mining operations or by waste-generated heat.

5. The very high thermal conductivity of salt will permit the dissipation of larger quantities of heat than would be possible in other types of rock.

6. The structural configuration of most salt deposits will permit horizontal mine development, allowing the use of suitable vehicles in underground transportation.

7. Salt is impervious to the passage of water because of its plasticity and crystalline structure.

8. Salt is not associated with potable water.

9. Fractures that might develop would be self-healing.

10. Principal areas of salt deposits are in regions of very low seismicity; the possibility of mine collapse due to earth movements would therefore be small.

11. Mining of salt is relatively inexpensive, compared to other rock types, so the cost of repository development in salt would not impose an unnecessary burden on the public.

In the early 1970's, work resumed at a low level in the search for suitable sites for waste repisitories. This work expanded rapidly in 1976 with the formation of the National Waste Terminal Storage Program. With the creation of this program, both funding and activity have been rapidly accelerating. Following the earlier recommendation of the NAS-NRC, the emphasis of the work has been on salt, but some surveys of a rather preliminary nature have been done on other rocks as well. Progress in some of these non-salt media were reported on in the previous session. With the completion of the recent Interagency Review Group report on the entire waste management program, efforts in non-salt rocks are expected to be stepped-up in the coming months and years.

Salt deposits of one kind or another underlie areas in many regions of the United States. Evaluation of these salt occurrences has been completed in virtually all of these areas and has shown that the deposits having the greatest potential for the siting of a waste repository are those of the largest depositional basins and the salt domes of the Gulf Coast region. Present activities are therefore being directed at those regions. The present program is directed toward characterizing progressively smaller areas in increasing detail, from both geologic and environmental viewpoints. Assuming that suitable sites are found to exist, the studies will culminate in a number of site recommendation documents that will represent a balance of geological and environmental factors. These documents will be backed-up by geological and environmental site characterization reports. The screening and winnowing process will represent one method of addressing the question of alternatives, which is"required by the National Environmental Policy Act.

From the geologic side, the principal topics that are being addressed are erosion and denudation, stratigraphy, structure-tectonics, seismicity, energy and natural resources, surficial and groundwater hydrology, and future geologic events. Nongeologic factors that are being addressed include atmospheric and climatic conditions, background radiation and noise, demography, socio-economics, land use, and terrestrial and aquatic ecology.

In the northeastern part of the country, bedded salt deposits underlie parts of Michigan, New York, Ohio, and Pennsylvania in the Appalachian and Michigan Basins. These deposits are strategically located with respect to the nuclear power industry 
as there are already numerous operating reactors within the region. Environmental and geologic characterizations have been completed on a regional scale and have resulted in the recommendation of smaller areas in New York and Ohio that are thought to have favorable characteristics for a repository. The studies that are needed to better define the suitability of these areas have now been delineated and an exploration program outlined.

In the Gulf Coast region, a number of studies related to the feasibility of utilization of salt domes for radioactive waste disposal have been completed over the past several years. The U.S. Geological Survey first examined salt domes in the region in 1973. An engineering feasibility study was completed by the University of Texas, College of Engineering, in 1975. Louisiana State University and the USGS began detailed investigations of the salt domes and the regional hydrology in 1974 that are still ongoing. Data on the hundreds of salt domes that exist in the region have been evaluated and the overwhelming majority of the domes rejected because of conflicting use related to petroleum or other natural resource exploration, unsatisfactory defth or size considerations, or uncertainties about tectonic stability. A small number of domes in the interior basins of East Texas, Louisiana and Mississippi have been selected for further evaluation and field evaluations of these domes are well underway. Geologic activities already in progress include seismic and gravity surveys, field geologic mapping, interpretation of remote sensing data, hydrologic testing, and monitoring of surface water flow and characteristics. In addition, deep core-holes have been completed in two salt domes in Louisiana. From the environmental side, a regional characterization has been completed, and characterization of areas around the domes still under consideration is expected to begin shortly.

In the Paradox Basin, where salt anticlines underlie portions of Colorado and Utah, evaluation of the salt deposits was begun by the USGS in 1973. Based on their recommendations, one of the salt structures in Utah, the Salt Valley Anticline, is being subjected to intensive geologic investigations. Activities conducted in the past year include drilling a 3-hole test pattern to obtain cores and hydrologic data, and vertical seismic profiling to determine the internal structure of the sait anticline. A regional environmental characterization report has been completed and work on the regional geologic characterization is well underway. Based on these two reports, it is expected that other salt structures within the basin will also be identified as having some potential for siting of a waste repository.

In the Permian Basin, which underlies portions of Colorado, Kansas, Oklahoma and Texas as well as eastern New Mexico, a regional geologic evaluation was completed in 1976. The purpose of this investigation was to determine if areas other than southeastern New Mexico, where the WIPP project is ongoing, might also have some potential for siting a repository. That investigation identified the Palo Duro subbasin in the Texas Panhandle as having the greatest potential. This sub-basin might have been identified earlier except for the paucity of geologic data which reflects the lack of geologic exploration activities for oil and gas as weil as mineable resources. A full geologic evaluation of the Palo Duro basin was begun in 1977 and is still underway. Additionally, a regional environmental characterization has been completed for the Permian Basin as a whole. This characterization also identified the Palo Duro sub-basin as having the greatest potential for siting of a waste repository. Based on both geologic and environmental considerations, it is anticipated that small areas within the Palo Duro sub-basin having the most fotential will be identified later this year. 


\section{2}


WIPP FACILITY DESIGN

Leo H. Scully

Sandia Iaboratorles

The design of a geologic repository for nuclear waste material is in many ways identical to the design of any warehouse. There are areas, however, where distinct differences exist; for example, both nuclear and nonnuclear facilities receiving and inspection, vehicle and facility maintenance, adninistration, and a host of other support functions. Design differences appear in special ventilation needs, the requirements of monitoring and handling radioactive materials, the fact that the warehouse area is a few thousand feet underground and that the itens to be stored, in some cases, produce heat.

The general configuration of the facility is as shown in Figure 1. There will be one waste-handling building, divided into two areas, one for contact-handled transuranic contaminated waste (CH TRU), and the other for remote-handled transuranic contaminated waste (RH TRU), and experiments. Between the two sections of the building will be the shaft to lower the waste to the storage horizons. The CA facility is being designed to handle $500,000 \mathrm{ft}^{3}$ per year of $\mathrm{CH}$ TRU waste on a one-shift-per-day basis. On a three-shifts-per-day basis the rate would be approximately $1,200,000 \mathrm{ft}^{3}$ per year. Only solid waste forms will be received and will be packaged in boxes and 55-gallon drums. The RH facility will accormodate approximately two canisters per day of remote-handled solid waste. The canisters will be approximately 1 to 2 feet in diameter and 10 to 16 feet long. Access to the underground will be through four shafts: 1) men and materials and fresh air (16 feet diameter), 2) construction air exhaust and sait removal (14 feet dianeter), 3) storage air exhaust (14 feet diameter), and 4) waste-handling (19 feet dianeter). The storage area will be on two levels - the upper level, at approxinately 2100 feet, will be for $C H$ TRU waste, and the lower level, at approximately 2700 feet, will be for RH TRU and experiments. If there is a demonstration of spent fuel dispcsal, as proposed by the Department of Energy (DOE), it will also be on the lower horizon. The storage rooms on the upper horizon will be approximately 16 feet high, 45 feet wide, and 1800 feet long. The rooms on the lower horizon will 


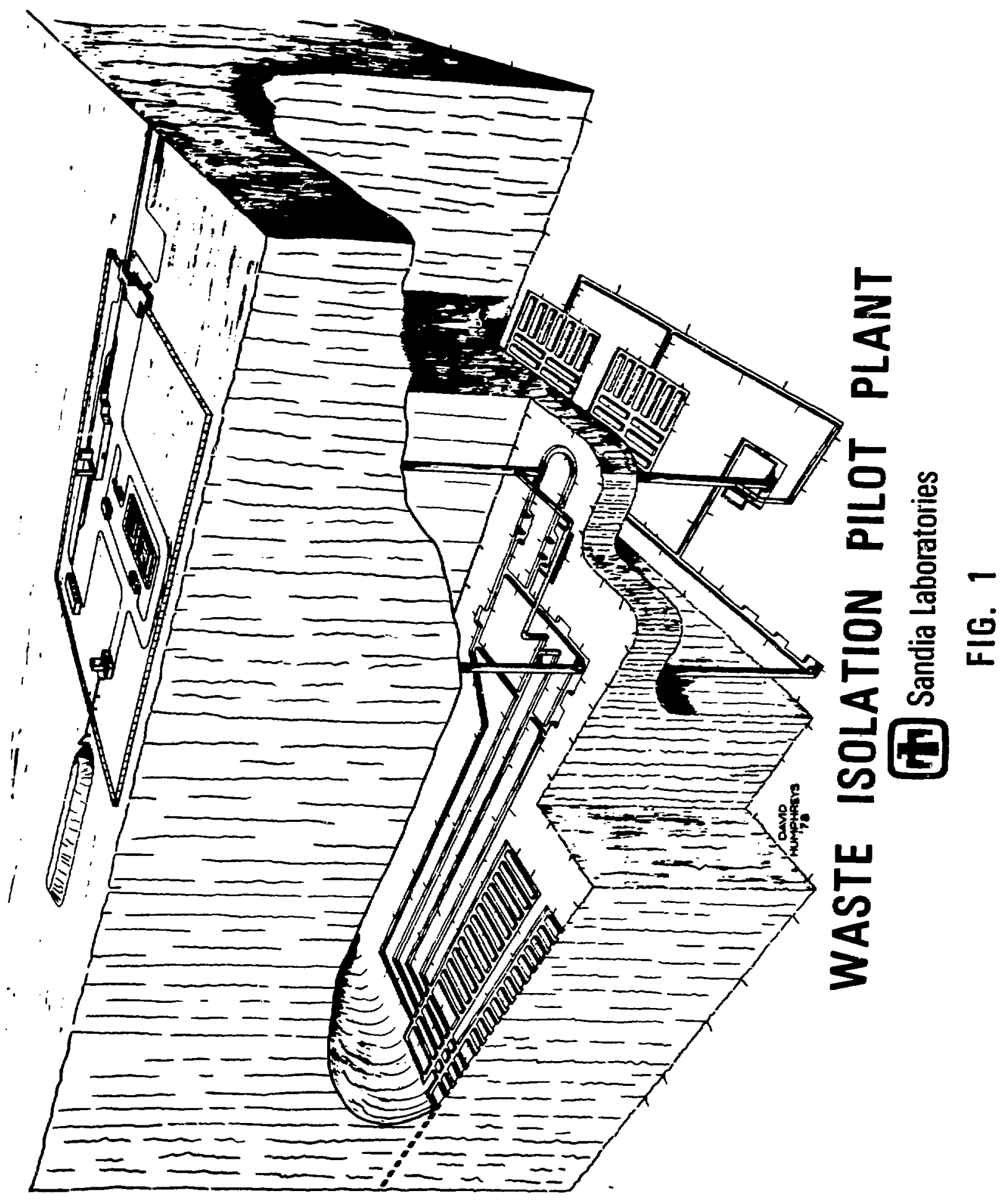


be smaller, approximately 24 feet high, 14 feet wide, and 500 feet long. On both horizons the storage rooms are developed off of a four-entry system, one for construction equipment and $f$ resh air, one for salt removal and construction air exhaust, one for waste storage operations and fresh air, and the last for storage air exhaust.

A much simplified sequence for $\mathrm{CH}$ TRU waste storage is depicted in Figure 2. The equipment and operations are essentially those of any warehousing operation where drums and boxes are handled. The sequence for RH TRU waste is depicted in Figures 3 and 4. For this type of material the surface dose rate is sufficiently high that shielded, remote operations are required. The waste will be received in licensed, heavy shipping casks and will be removed from this cask in a hot cell and transferced to a facility cask for transfer to the underground storage room. Once in the storage rom the waste container will be remotely lowered into a previously prepared sleeved hole in the salt and covered with a shield plug. The retrieval of both the $\mathrm{CH}$ TRU and the RH TRU (and spent fuel if present) will be a reversal of the storage operations.

Little damage from corrosion of the $\mathrm{CH}$ waste containers is expected even though the drums and boxes will be in direct contact with the salt. (The RH canisters will be in steel-lined holes and will not touch the salt.) Corrosion studies indicate that in a dry salt environment (less than 608 relative humidity), little corrosion occurs. If, however, for either corrosion or accidental damage, there should be any degradation of the waste package, it would be overpacked upon retrieval and before any off-site shipment.

The waste experiments, however, pose a more difficult retrieval problem. To produce meaningful results, the experimental waste material will be placed directly in contact with the salt. In some cases, the waste form will be deliberately degraded and corrosion products, brine, and possibly other materials and solutions will be placed into test configurations and instrumented. The development of equipment to extract samples and to retrieve the entire experiment by overcoring is in process. Thorough testing and demonstration under field conditions will be conducted before any waste material is actually emplaced in the experimental facility.

The basic design concepts used in the ventilation design is that air always flows in the direction of greater contamination potential and that facility personnel should always work upstream of stored waste materials. To implement these concepts, airlocks, dampers, and fans are used throughout the buildings, shafts, and underground storage areas for ventilation control. The underground area is further divided into construction and storage areas so that both the physical activities and the ventilation are separate. The ventilation flow diagram is shown in Figure 5. To maintain an air flow velocity in the waste storage of Erom 50 to 100 feet per minute and to supply the needs of the personnel, the diesel equipment, and to maintain clean air and remove the dust from the construction area, requires a considerabie quantity of fresh air. Approximately 300,000 cfm will flow through the storage areas and 120,000 $\mathrm{cfm}$ thruugh the construction areas. 


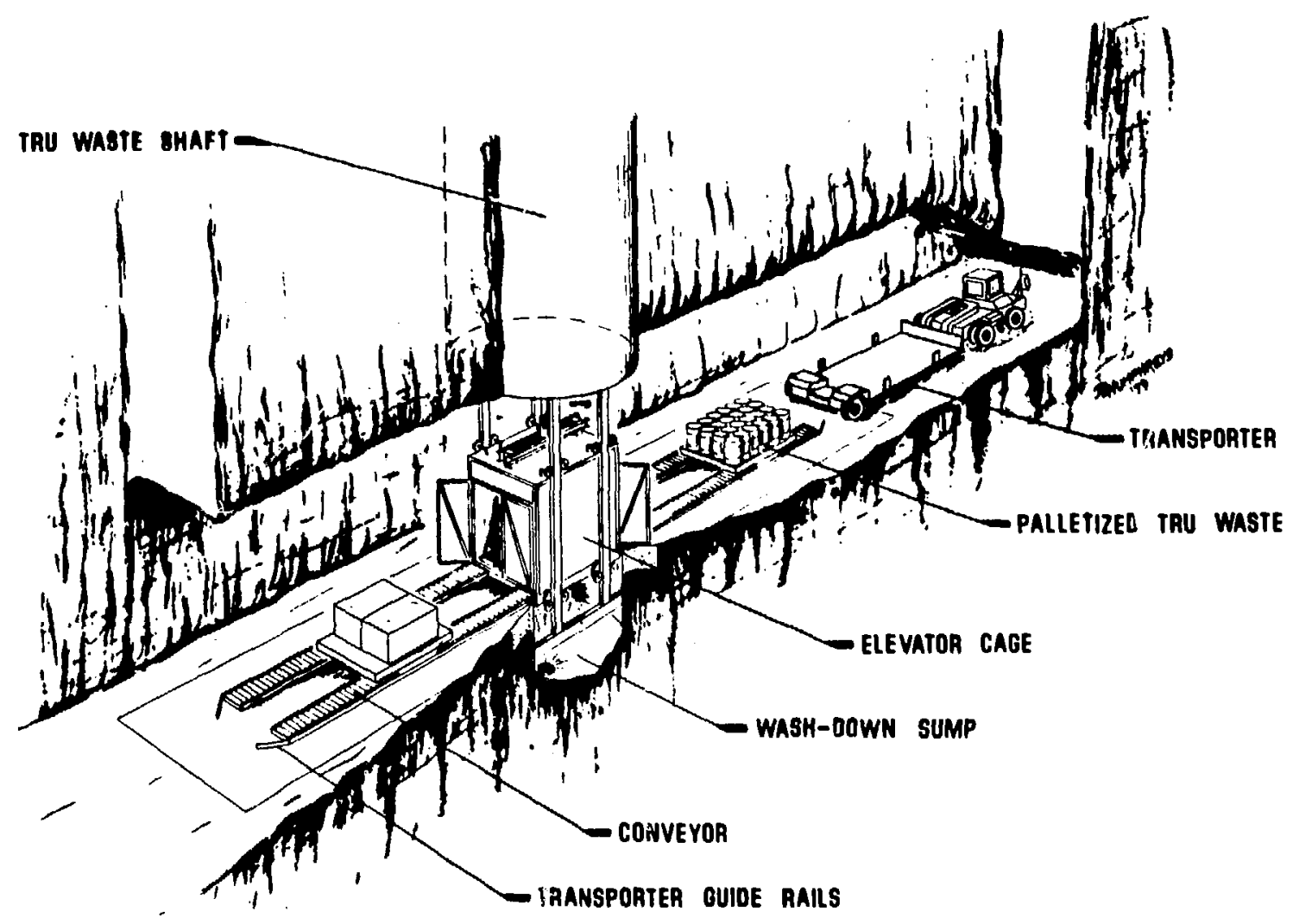

W.I.P.P. UNDERGROUMD TRU WASTE RECEIVING STATION

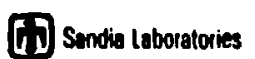

FIG. 2 


\section{REMOTE HANDLED WASTE FACILITY}

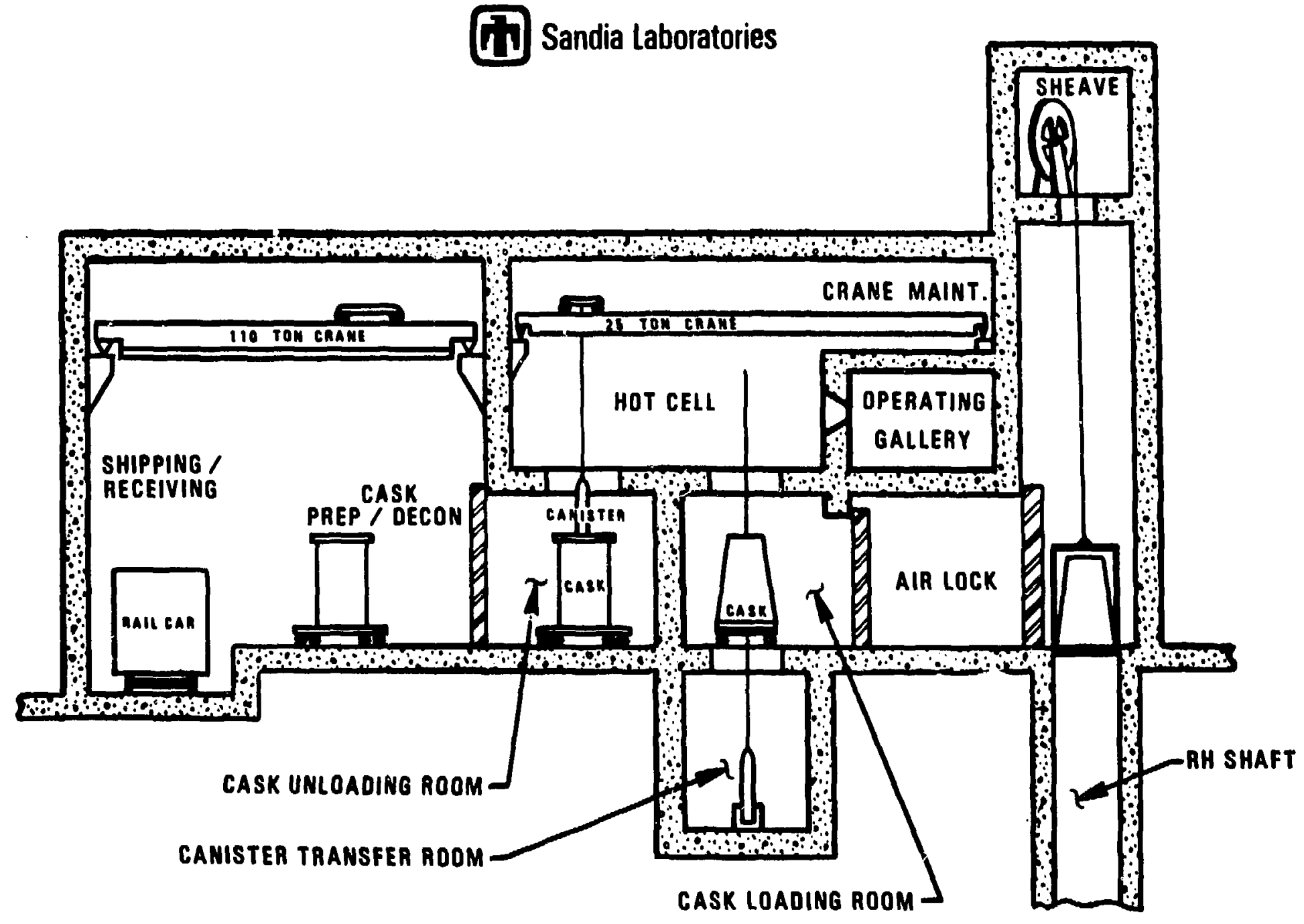

FIG. 3 


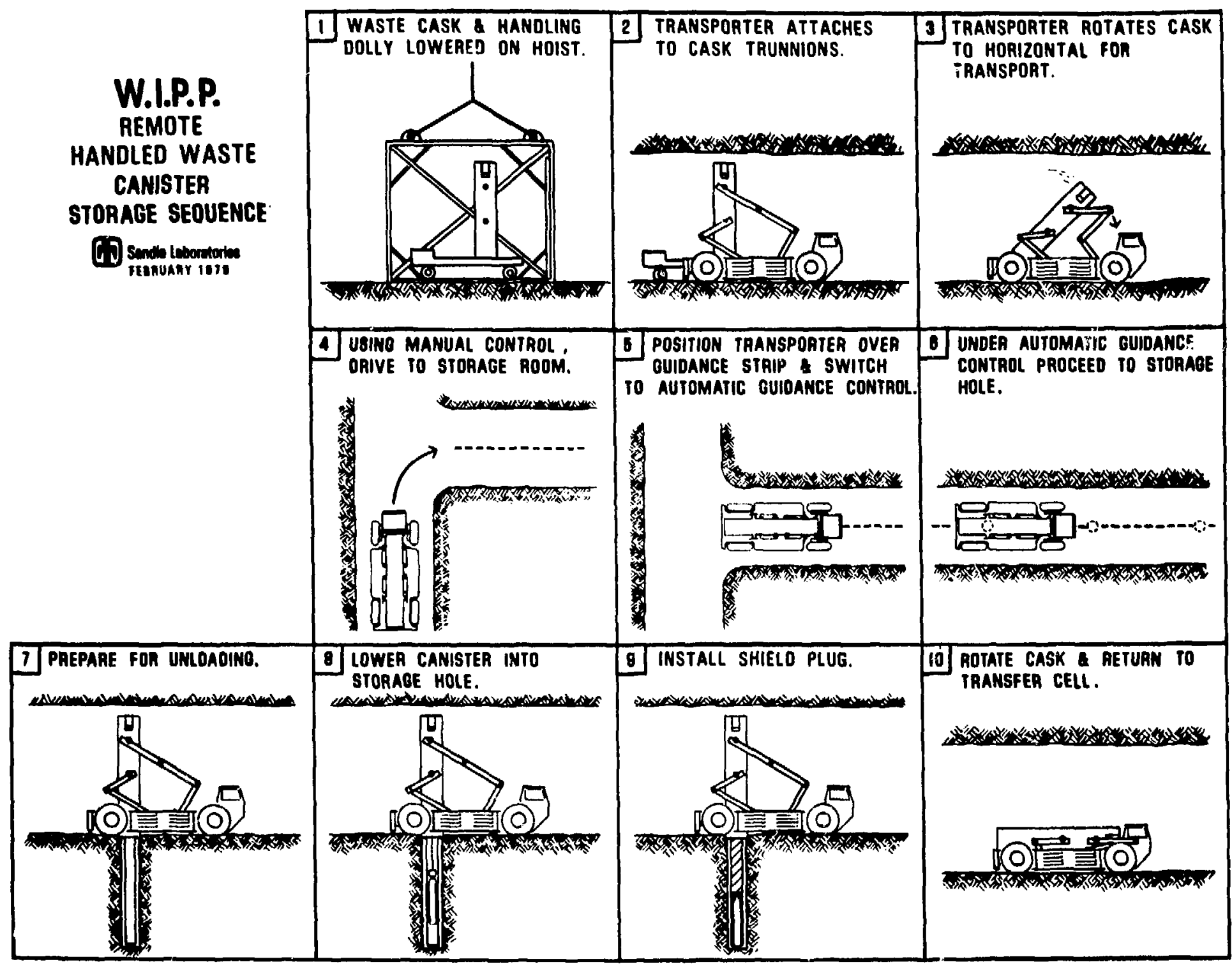

FIG. 4 


\section{UNDERGROUND VEMTILATION FLOW \\ (i) Sandia Laboratories}

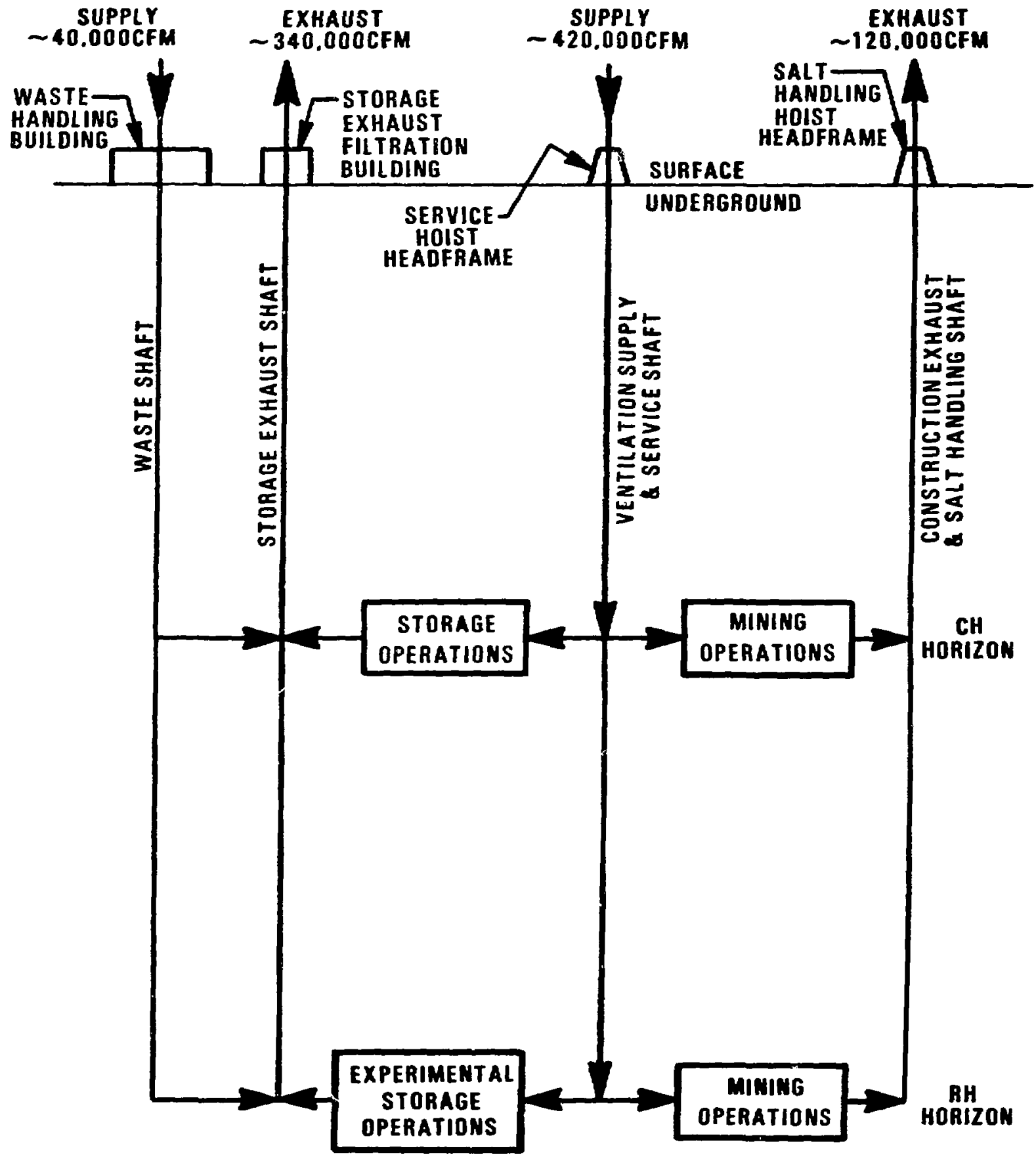

FiG. 5 
SITE EVALUATION FOR THE WASTE ISOLATION PILOT PLANT (WIPP)

Leslie R. Hill

Sandia Laboratories

The first radioactive waste repository in the United states is being planned to begin operation in the 1980 's. This facility, the Waste Isolation Pilot Plant (WIPP) to be located in southeast New Mexico, is planned to be a repository for transuranic (TRU) waste Erom past and current United States defense programs. In addition, the WIPP would provide a research facility to examine, on a large scale, the interactions between bedded salt and high-level radioactive waste. A U.S. Department of EnergY (DOE) Task Forcil has recommended that WIPP also be used to demonstrate surface and subsurface methods of handling, storing and disposing of up to 1,000 canisters of spent reactor fuel; however, a decision to implement this recomendation has not been made.

The proposed underground storage facilities are to be placed near the middle of a 3,600-foot-thick seguence of relatively pure evaporite strata containing primarily rock salt and anhydrite, lying between depths of about 500 and 4,100 feet beneath ground surface. Within this sequence, the formation richest in rock salt, the Salado Formation, is nearly 2,000 feet thick and contains the relatively pure salt layers in which the two proposed underground storage levels are to be constructed at depths near 2,100 feet and 2,650 feet. The storage horizons are well isolated from the environment by adjacent evaporite strata. A thickness of at least 1,300 feet of undisturbed evaporite rock, primarily rock salt, overlies the upper storage horizon and about an equivalent thickness of anhydrite and rock salt intervenes between the lower storage horizon and the next adjacent underlying non-evaporite formation.

1 Department of Energy, 1978, Draft Report of Task Force for Review of Nuclear Waste Management: DOE/ER-0004/D, no personal author, 166 p. 
Geologic studies performed over the past three years for the WIPP fall into three different phases: preliminary site selection activities, site characterization, and studies of long-range geologic processes affecting a repository. Preliminary site selection activities are complete now ${ }^{2}$, and site characterization is nearly complete ${ }^{3}$.

Preliminary site selection criteria were generic in nature. After Sandia Laboratories determined in 1975 that the first preliminary study area was geologically unsuitable, site selection factors were refined and applied to the Delaware Basin in New Mexico to define the present study area. Data from hundreds of borehole geophysical logs and more than fifteen hundred miles of existing seismic reflection lines from petroleum companies were analyzed and considered along with hydrologic data and available information on natural resources to narrow the area of search.

In the past three years, many standard petroleum and mineral industry techniques have been used to characterize the WIPP site. Geophysical surveys include about 140 line miles of new seismic reflection data and over 9000 resistivity measurements. Twenty-one boreholes were drilled to evaluate potash, and 18 hydrologic test holes are being used for shallow hydrologic studies. Fifteen stratigraphic test boreholes have been drilled on or around the WIPP site and two other holes have been drilled well away from the WIPP site to study dissolution processes. Two of these holes were drilled through the salt to test deep aquifers below the salt and acquire geologic data. Much investigative effort has been expended to define subsurface geologic conditions at the WIPP site. These studies not only provide detailed information regarding mining conditions at the repository levels, but also furnish a basis for an assessment of protection against possible modes of containment failure at the site, in the context of the long-term isolation requirements of radioactive waste.

Regional seismicity of the site has been investigated by a seismographic station installed near the site and an array of seismographic stations installed on the Central Basin platform near Rermit, Texas. The seismicity information is to provide a data base for design of facilities. Seismicity information also serves as an indicator of the tectonic situation in assessing the WIPP site for a repository.

Hydrologic studies of the proposed site and adjacent area are directed toward a quantitative evaluation of the salt dissolution process, the hydrogeologic parameters affecting groundwater movement, and the major elements of surface and groundwater quality as related to water resource use. The collection of hydrologic data is projected to continue for several years to provide site-specific information for a detailed safety analysis of the wIPP. Climatological records show that mean annual precipitation at the site is approximately 12 inches per year.

2 Griswold, G. B., 1977, Site selection and evaluation studies of the waste Isolation Pilot Plant (WIPP), Los Medanos, Eddy County, New Merico: Sandia Labor atories Report SAND77-0946, Albuquerque, NM, December 19\%7.

3 Powers, D.W., et al., 1978, SAND78-1596, Geological Characterization Report for the Waste Isolation Pilot Plant (WIPP), Southeastern New Mexico. 
The only major stream near the site is the Pecos River which flows southeasterly through Carlsbad. At its closest point, the river is approximately 14 miles southwest of the WIPP site. The minimum surface elevation of the site is more than 310 feet above the historic flood level.

Surface drainage patterns at the site are undeveloped. The nearest groundwater is more than $\mathbf{5 0}$ feet below the land surface. Most infiltration escapes the soil through evaporation and transpiration.

Groundwater within the Delaware Basin is predominantly of poor quality with total dissolved solids concentrations typically in excess of 3,000 ppm. The only large quantities of potable groundwater are found in aquifers west of and along the Pecos River. Groundwater velocities in the surrounding formations typically range from 0.0005 to $0.5 \mathrm{ft} /$ day, depending on the particular rock unit. The thick halite beds of the Salado Formation are isolated from circulating groundwaters by confining layers of low hydraulic conductivity, directly above and below the salt formation.

The geochemistry of the proposed WIPP site shows that the mineralogy of most of the rock salt is relatively simple. The evaporites have been recrystallized, resulting in some mineral assemblages different from those precipitated from original sea-water-like solutions at one time present in the Delaware Basin. The last episode of such recrystallization took place more than 200 million years ago.

Potash salts and natural gas are the two resources of economic significance under the WIPP site. Potassium salts occur in a variety of mineral types, but only sylvite and langbeinite are currently economic. The U.S. Bureau of Mines has judged that a langbeinite deposit located in the northeast quadrant of the wIPP site could be profitably mined using today's technology. Several deposits of sylvite are present in the WIPP site, but none would be developed under today's economic conditions. Natural gas is being produced in Southeast New Mexico. About 37 billion cubic feet of natural gas accompanied by about $0.5 \mathrm{mill}$ ion barrels of distillate are statistically estimated to be economically recoverable from the site area.

In sumary, preliminary site selection activities for the WIPP are complete now; these consisted primarily of national and regional studies over the past fifteen years, and resulted in selection of the WIPP study area for geological characterization. The work of geological characterization should be considered to have begun with the drilling of ERDA 9 at the center of the WIPP study area and the initiation of seismic reflection work on the site. That geological characterization, which is primarily oriented to provide specific data concerning the present geology of the site, was virtually complete in December, 1978, when the Geological Characterization Report was submitted to the Department of Energy; much basic information has been gathered indicating no major technical problems with the site as it is now understood. Studies of long-term processes which might affect a repository or have an effect on safety analyses will now be the major geotechnical activity for the WIPP site evaluation team, some of these activities are already underway. These studies will deal with the age of significant features and the rates and processes which produce those features. The information so gained will be useful in increasing the confidence in evaluation of the safety of a repository. 
TECHNICAI, ISSUES FOR WIPP

Thomas D. Hunter

Exper imental Programs Division

Sandia Laboratories

Albuquerque, New Mexico

\section{Introduction}

Implementation of the WIPP will require a commensurate technology development program which will both support the design and operation of the facility and provide the basis for assuring that deleterious impacts on public safety or the environment do not occur. The current design, therefore, in addition to providing for a facility which allows the retrievable storage of defense transuranic wastes and a demonstration of spent-fuel disposal, also incorporates an area for retrievable experiments on heat producing waste forms. These experiments will provide the necessary resolution of technical issues regarding permanent disposal of spent fuel or HLH in bedded salt.

An objective assessment of these elements of the WIPP mission has revealed several technical issues which are currently being addressed by research and development activities at Sandia Laboratories. These activities currently consist of development of predictive models, laboratory analyses for corroboratory data, and bench-scale tests for larger-scale investigations and assessment of synergistic effects. In addition, plans are in progress for development of an "underground laboratory" in southeastern New Mexico for in situ experiments which will provide full-scale investigation of rocksalt responses to non-radioactive sources. These field experiments are anticipated to be in progress by mid-1979. These various activities form the sequential steps which culminate in waste emplacement and initiation of experiments with radioactive waste forms in the 1986 time frame if the WIPP project is approved..

These R\&D activities are viewed as necessary steps to quantify and reduce the uncertainty associated with various technical issues. Projections, however, of potential impacts of these issues on public safety, using very conservative bounding calculations, indicate that waste disposal in WIPP salt beds is quite safe. Therefore, continued development of the WIPP can proceed relying on further analysis and experimentation to provide additional measures of safety assurance. 
The principal technical issues which this program addresses are:

- The interaction of transuranic wastes with the salt environment including assessment of potential degradation mechanisms and the impact on the repository and racionuclide isolation.

- The interaction of thermal and radiation fields from heat producing wastes with the salt environment and the impact on the waste form encapsulating materials.

- Prediction of the response of the host rock to both the ambient conditions upon excavation and the enhanced deformation anticipated with heat-producing waste forms.

- Characterization of the potential for radionuclide migration in the WIPP environment.

- Characterization of the properties of the host rock for permeation of gases or liquids.

- Assessment of the potential for mobilization of natural fluids in the salt and the subsequent interaction with waste conta'ners.

- Quantification of the technology for sealing man-made penetrations into or near the storage horizons.

- Demonstration and certification of safe operational techniques and appropriate design assumptions.

Each of these issues is being methodically evaluated to accumulate additional definitive data and to correlate all available knowledge into an assessment of the potential consequences to the integrity of the waste isolation mechanisms.

\section{Interaction of Transuranic Waste Form}

While the majority of transuranic-contaminated wastes are contact-handled and emit little heat or penetrating radiation (approximately 0.04 watts/55 gal drum and less than $200 \mathrm{mrem} / \mathrm{hr}$ surface dose rate), degradation in the WIPP environment should be investigated. The potential exists for radiolytic, pyrolytic, chemical, and bacterial degradation mechanisms. Degradation products could include gases whose presence would inhibit closure of the waste rooms. Laboratory studies of these interactions have been initiated, and a summary of early results under ambient and maximum credible conditions $\left(70^{\circ} \mathrm{C}\right.$ and 150 Bars) has been recently made by $M$. A. Molecke (Sandia Laboratories). 1 These results indicate that the most significant gas production may be due to bacterial interaction if such organisms can survive in the mine environment.

Additional concerns being addressed are the alteration of radionuclide chemical forms so that the sorptive characteristics are reduced, thereby enhancing migration potential, and an assessment of the integrity of the waste containers to operational and long-term isolation environments. 
Both spent fuel and high-level waste forms can produce thermal porer at initial rates on the order of $0.5-5 \mathrm{kw}$ per canister and surface radiation dose rates of $10^{5} \mathrm{rem} /$ hour of penetrating radiation. These fields could produce local salt temperatures from 80 to $250^{\circ} \mathrm{C}$ depending on emplacement power density and power per canister. Laboratory investigations are underway which will assess the potential for leaching of various waste forms and corrosion of candidate canister or overpack materials. Studies made under maximun credible conditions of temperature and pressure with brine inundation indicate that, while certain waste forms may degrade if these conditions exist, canister materals have been identified which could prevent any direct interaction with the waste form during the period of significant thermal output ( $t^{1 / 2}$ of approximately 30-50 years).$^{2}$

Titanium-based alloys, for example, have shown corrosion rates of less than $10^{-3} \mathrm{~cm} /$ year at $250^{\circ} \mathrm{C}$ in representative NIPP brine under oxygenated conditions. The most serious criterion for canister integrity may, however, be imposed by the requirements for retrieval which include sufficient mechanical strength to accommodate stresses induced by load creep of the rocksalt.

Additional studies are being made of the production of stored radiation danage energy and associated various annealing mechanisms in the WIPP mi..eralogy and the effect of radiolysis on interaction chemistry.

\section{Rock Response}

Prediction of rock response during mining and operation and after decommissioning will be required to quantify impacts on the biosphere. Both finite element and finite difference computer models have been developed to model the temperature, stress, and displacement fields which are anticipated. Laboratory analysis of the elastic and creep properties of rocksalt have been underway for several years. Various creep models have been formulated which have been based on these laboratory measurements. These models have been compiled recently and summarized by Dawson ${ }^{3}$, while Wawersik has sumarized the results of quasi-static and creep tests on WIPP rocksalt. 4 Bench-scale experiments with electric heaters are currently in progress. In situ testing of mine response to excavation has been done on a limited scale in southeastern New Mexico (SENM) potash mines and will be carried out on a much larger scale, including the effect of electric heaters, when an area dedicated to such experiments is obtained. When construction begins, the excavation of the WIPP facility will be carefully monitored to obtain rock mechanics data.

All th is information will be integrated into the development computer modeling including appropriate constitutive models. These models can then be used to predict such canister-scale phenomena as confining stress, local temperatures, and potential for canister buoyancy. In addition, room-scale calculations are performed to predict closure cates, and regional-scale calculations are performed to assess temperature changes and deformation in overlying formations.

Calculations have been performed using the models and the existing data on rock properties which have estimated the limits of canister motion relative to the 
salt ${ }^{5}$, the potential For uplift of the repository $y^{6}$, and the effects of various canister emplacement configurations.

Migration of Radionuclides

Estimates of the consequences of postulated catastrophic events have assumed that waste forms are carried away by groundwater intrusion from overlying or underlying formations. Prediction of the potential dose to representative local populations require knowledge of the sorptive properties of both aisposal horizons and overlying strata. Laboratory studies are being carried out with both batch and flow-through techniques to gather sorptive data. In addition, laboratory development of artificially emplaced barriers (getters) is in progress.

Results to date have identified distribution coefficients $\left(K_{d}\right)$ of 2500 or greater for plutonium in WIPP aquifers and have also indicated significant retardation due to impurities in the salt with $K_{d}$ on the order of 20 to 60.8 In addition various clays, including some natural to the WIPP site, have been identified as potential getter materials via the mechanisms of precipitation and physical sorption, ion exchange and chemical sorption, or flow barriers. Additional studies will provide more precision on a wider range of radionuclides and thus serve to enhance the confidence levels for prediction of radionuclide release potential.

Permeability of Rocksalt

If gas is generated from waste degradation, it is necessary to predict the ability of these gases to diffuse away from the storage location in order to assess the consequences to the repository. Laboratory permeability studies have been made on WIPP site core in which confining pressures were reestablished in triaxial compressive testing machines. These results indicate that permeabilities are less than 100 nanodarcies after specimens "heal." Additional studies will be carried out under in situ conditions in boreholes near the WIPP site in late spring of 1979.

\section{Migration of Fluids}

Iimited data are available on the potential for migration of brine inclusions which are known to be present at about $1 / 2$ percent by weight or less in bedded salt typical of the proposed WIPP sice. While any impact of the migration toward heat sources may be inconsequential, the significant public controversy on this matter requires development of quantitative data to support a realistic assessment of any consequences. As a result, laboratory studies are underway, and a bench-scale experiment on a one-meter-diameter salt block was initiated in December 1978. These experiments will characterize and measure the mechanisms and associated migration rates of any contained brines. In situ experiments will be carried out in 1979 which will measure these same phenomena with heaters in SENM potash mines. While these studies will quantify specific mechanisms for brine migration, several possible engineering solutions, e.g., liners or brine gettering materials, will also be evaluated. 


\section{Borehole Plugging}

The requirements to assess the potential for fluid migratin in man-made penetrations near waste repositories necessitates the careful study of the technology for plugging boreholes. Studies on the emplacement and stability of cementitious grouts and the potential for natural materials as candidate plugging materials will be performed. These studies of materials will be accompanied by commensurate field tests and the development of instrumentation to evaluate plug performance. These programs will be based on the use of field tests to assess and demonstrate near-term concerns such as emplacement techniques, leakage potential, and strength while relying on laboratory studies to address the long-term issues of plug-media compatibility and geochemical stability. While conseguence assessment studies indicate that the assumption of open boreholes with fully established flows through the repository does not present a significant safety hazard, the experimental program will allow assessment of the additional protection provided by hole plugging.

\section{Operation and Design Investigations}

The appropriateness of the facility design and the efficiency of final facility operation can best be evaluated through demonstrations which model or duplicate expected design features. Consequently, studies are being planned to provide these studies both in the laboratory and in SENM mines which will evaluate waste handing methodology including retrievability hardware and techniques for both TRU waste forms and heat-producing wastes. In addition studies relating to ventilation, drilling, communication, scanning of intact salt for anomalies (such as nitrogen pockets) before mine advancement, and radiation background are underway.

\section{SUMMARY}

Enplacement of wastes in the WIPP will include experiments on various waste types which will provide essential data on waste-rock interaction and repository response. These experiments will include evolution of the synergistic effects of both heat production, radiation, and actual waste forms. While these studies will provide essential data on the validity of waste isolation in bedded salt, they will be preceded by a broad-based experimental program which will resolve many of the current technical issues providing not only an assessment of the safety of performing such experiments but also the technical basis for assurance that the appropriate experinents are performed. Data and predictive modeling techniques, whirh are currently available, can bound the consequences associated with these technical issues. Predictions of the impact on public safety based on these analyses indicate that safe waste disposal in WIPP salt beds is achievable; however, a major use of WIPP will be to conduct realistic experiments with HLW forms to address some of the unresolved details of these waste/salt interactions.

\section{REFERERCES}

1. M. A. Molecke, "Gas Generation from Transuranic Waste Degradation: An Interim Assessment," SAND 79-0117 (to be published). 
2. J. W. Braithwaite and M. A. Molecke, "High-Level Waste Canister Corrosion Studies Pertinent to Geologic Isolation," SAND78-21ll (preprint). To be published in Nuclear Waste Management and Technology, $1(1), 1979$, Pergammon Press.

3. P. R. Dawson, "Constitutive Models Applied in the Analysis of Creep of Rock Salt," SAND79-0137, February 1979.

4. W. R. Wawersik, "Interim Sumary of Sandia Creep Experiments on Rocksalt for the WIPP Study Area, SENM," SAND79-0115, February 1979.

5. P. R. Dawson and J. R. Tiilerson, "Nuclear Waste Canister Thermally Induced Motion," SAND78-0566, June 1978.

6. F. R. Dawson and J. R. Tillerson, "Salt Motion Following Nuclear Naste Disposal, Proceedings of the International Conference on the Evaluation and Prediction of Subsidence, Pensacola, FL, January 15-20, 1978.

7. P. R. Dawson and J. R. Tillerson, "Comparative Evaluations of the Thermomechanical Responses for Three High Level waste Canister Enplacement Alternatives, SAND77-0388, December 1977.

8. R. G. Dosch and A. W. Lynch, "Interaction of Radionuclides with Geomedia Associated with the Waste isolation Pilot Plant (WIPP) Site in New Mexico, SAND78-0297, June 1978. 
MIPP SAFETY ASSESSHENT

J. P. Brannen

Sandia Laboratories

\section{INTRODUCTION}

This paper summarizes the efforts to perform a safety assessment of the wIPP facility being proposed for southeastern New Mexico. Consequences of the events which result in loss of containment are of fundamental importance when making site seiection, design decisions, and waste form acceptance criteria. This preliminary safety assessment of the WIPP facility is limited to a consequence assessment in terms of the dose to a maximally exposed individual as a result of introducing the radionuclides into the biosphere. No attempt has been made to extend the consequences to population dose or to weight the dose with probabiiity of the events.

Inherent in the methodology developed for this analysis are several assumptions that were required to reduce the problen to one that could be approached with the available cesources and data. These include the following:

Static ecology and biosphere pathways

Breach event does not alter geology from that now observed

Parameters that affect geosphere transport remain constant during transit

Transfer coefficients for biosphere pathway components are independent of soil and chemical compounds that contain the radionuclides 


\section{METHODOLOGY}

The WIPP analysis methodology is similar to the basic methodology used in earlier studies in that it evaluates the consequences of hypothetical future events that could cause loss of containment from the repository. It differs from previous studies in several major aspects. First, the wastes are not assuned safe after any period of time. Consequences are evaluated as a function of time after each release event intil a maxima is reached. Secondly, the repository is assumed to contain contact-handled TRU waste. Previous studies have been limited to highlevel waste. Thicd, the analysis used detailed geologic, hydrologic, and ecologic data for the WIPP site and thus is site specific. These aspects of the analysis make it directiy applicable to the WIPP conceptual design and waste acceptance criteria.

The methodology involves several distinct steps leading to the final safety parameterization of the facility. The basic step was the identification of the scenarios resulting in loss of containment. The scenario description includes identification of a breaching event, a physical mechanism for transporting the waste through the breach, and the response of the storage mediun to the event. Once a scenario is determined, a mathematical model is constructed describing the transport process in the modified media. This model is utilized to determine the concentration of the various radionuclides as a function of temporal and spatial coordinates in the modeled region for a particular inventory. The radionuclides are then in a media accessible to man via natural or anthropogenic pathways. For WIPP, the natural pathway is the discharge of the Rustler aquifer into the Pecos River at Malaga Bend. The anthropogenic event analyzed is the result of exploratory drilling for natural resources and directly intercepting the reposicory.

When the raionuclides enter the biosphere, they are transported to a maximally exposed individual. The term "maximally" mians that contaminated material or area provides all of the various exposures the individual receives. For example, all fish that are consumed come from the contaminated Pecos Rive:. However, the individual's exposure time and food consumption are average values determined from site-specific data. The consequence parameter is the 50-year dose commitment from one year of exposure.

The safety assessment was performed for five breaching scenarios. These scenarios were chosen for their representativeness of worst-case events. Scenarios 1 through 4 represent a 11quid breach of the repository with the subsequent transfer of the waste materiai through the Rustler Formation. The fifth scenario represents breach by a drilling activity which brings waste directiy to the surface. All events were assimed to occur 1,000 years after decommissioning of the facility.

Scenario 1 represents a connection between the Rustler and the Bell Canyon aquifers through a failed well shaft. The Bell Canyon aquifer is located below the Castile Formation in the Delaware Mountain Group. Scenario 2 represents connection to the Rustler at both ends of the repository through a well bore and access shaft seal failure. Scenario 3 is a single connection between the repository and the Rustler aquifer resulting in a diffusion of the waste into the aquifer. Scenario 4 is of interest as a bounding condition. In this scenario, the total flow in the 
Rustler over the entire width of the repository passes through the repository and back to the Rustler Formation.

The Rustler Formation consists of two aquifers, the Culebra and Magenta, which flow to the southwest and empty into the Pecos River at Malaga Bend. These two aquifers were modeled as a single aquifer. Two values for the permeability of the formation furnished upper and lower bounds on the transport rate of the materials through the geosphere. The waste material was assumed to be leached out of the repository at the same rate as the salt. The additional density due to the material in solution was igtiored. These conditions produce upper bounds on the amounts and rates of release of the waste.

Sceisario 5 was modeled to determine the consequence of directly accessing the repository contents after decommissioning as a result of drilling activity in the region. Two cypes of drilling activity were considereả. Mineral exploration was modeled as a 3 inch borehole with continuous coring bringing up cuttings diluted in the drilling fluid. Oil and gas exploration was nodeled as a 10-inch borehole with chip coring, resulting in waste being brought to the surface diluted by drilling fluid present in the mud pit.

\section{GEOSPHERE TRANSPORT}

The numerical model used for geosphere-transport calculations was developed by INTERA Environmental Consultants, Inc., For the US Nuclear Regulatory Commission. It is a modified version of deep-well disposal model developed by INTERA for the US Geological Survey. This three-dimensional, finite-difference model solves a set of partial differential equations describing total flow, energy, salinity, and radionuclide transport in a porous medium. The equations are coupled by the density and viscosity of the fluid. Details of the model are given in Reference 1.

Geosphere-transport calculations were confined to the Rustler Formation with the discharge point at Malaga Bend on the Pecos River. The potential contours in the Rustler indicate that flow between the repository and Malaga Bend is essentially one-dimensional toward the Pecos River and that all water from the Rustler discharges into the river. Steady-state potentials from scenari modeling were used to represent the boundary conditions for the nuclide transport. Calculations were performed up to 100,000 years after the initiation of each scenario.

\section{BIOSPHERE TRANSPCRT MODELING}

The biosphere transport models define the pathways by which the radionuclides become availabie as dose to man. This assessment relied heavily upon existing codes Eor reasons of both accountability and acceptability. The codes used were developed by various government agencies and laboratories and are widely used in the performance of risk assessment calculations associated with other aspects of the nuclear fuel cycle. The primary codes and their developing agency are listed in table 1 . 
TABIE 1. CONSEQUEHCE ASSESSMERT CODES

\begin{tabular}{|c|c|c|}
\hline Code & Agency & $\frac{\text { Use }}{\text { LIOUID TRANSPORT }}$ \\
\hline TERMOD & ORNL & TERRESTIAL TRANSPORT \\
\hline INRER & ORNL & INIERAAL DOSE \\
\hline EXREA & ORLL & EXTERARL DOSE \\
\hline CDMQC & EPA & AIR TRANSPORT \\
\hline
\end{tabular}

These codes were interfaced using routines specific to the WIPP site. The exposure pathways for the liquid breach scenarios included ingestion of contaninated water and aquatic food and external exposure from swiming, boating, and shoreline recreation. Two exposure pathways were considered in the aralysis for the direct-access release scenario: The direct external exposure of the drillcrew members and the geologist involved in the sample collecting; and wind erosion of the mud pit with subsequent atmospheric dispersion and depositon downind. Man is exposed through inhalation, ingestion of crops, meat, and milk, and to external exposure from the ground surface. The data, programs, and program interfaces required to implement the biosphere transport models are discussed in detail in reference 2 .

\section{CONSEOUEANCE ASSESSIENT}

With the scenarios defined and the various models to represent the geospheric and biospheric pathways developed, the safety assessment for various inventories may be addressed. With the exception of early-time thermal loads, the models developed are independent of the inventory contained within the facility. For this assessment, the inventory was based upon actual assay data from the Idaho National Engineering Laboratory for contact-handleã TRU waste.

of the four liquid breach scenarios, scenarios 1 and 4 represent the worst cases. Maximum doses occur approximately 100,000 years after the breaching event for the upper permeability. For the lower permeability, no radionuclides enter the biosphere in the first 100,000 years.

\section{TABLE 2. LIQUID BREACH CONSEQUENCES}

\begin{tabular}{ll} 
Organ & \multicolumn{2}{l}{ Scenario 1} \\
Liver & $2.0 \times 10^{-9}$ \\
Skin & $2.7 \times 10^{-9}$ \\
Bone & $4.5 \times 10^{-6}$ \\
Thyroid & $2.0 \times 10^{-9}$ \\
Body & $1.2 \times 10^{-6}$ \\
GI-LI & $2.4 \times 10^{-7}$ \\
Lung & $2.0 \times 10^{-9}$ \\
Kidney & $7.5 \times 10^{-7}$
\end{tabular}

Dose (rems)

Scenario 4

$2.6 \times 10^{-6}$

$3.3 \times 10^{-6}$

$4.9 \times 10^{-3}$

$2.5 \times 10^{-6}$

$2.0 \times 10^{-3}$

$1.0 \times 10^{-4}$

$2.4 \times 10^{-6}$

$5.0 \times 10^{-4}$ 
TABLE 3. DOSES FROM GENERAL SOURCES

Source

Television

Consumer Products

Air Transport

Medical

Background
Dose (rems)

$$
\begin{array}{r}
1 \times 10^{-4} \\
1 \times 10^{-3} \\
7 \times 10^{-3} \\
90 \times 10^{-3} \\
100 \times 10^{-3}
\end{array}
$$

For scenario 5 , in which the repository is penetrated by a drilling operation, the consequences are substantially higher. The primary cause for this is the immediacy of the dose since the time delay element, which is the principal motivation for deep geologic storage, is eliminated. The doses to drill crew members from chip and core samples and to the maximally exposed individual as a result of inhabiting the area downwind from the mud pit are presented in table 4. The primary exposure mode for the indirect pathways is inhalation.

TABLE 4. DOSE FROM DIRECT ACCESS TO CH WASTE REPOSITORY (REMS)

\begin{tabular}{llc} 
Borehole & $\begin{array}{c}\text { Drill Crew } \\
\text { Member }\end{array}$ & $\begin{array}{c}\text { Individual Bone Dose } \\
\text { Erom Indirect Pathways }\end{array}$ \\
\cline { 2 - 2 } $\begin{array}{c}\text { 10-inch diameter } \\
\text { 3-inch diameter }\end{array}$ & $\begin{array}{l}1.5 \times 10^{-5} \\
6.0 \times 10^{-4}\end{array}$ & $\begin{array}{l}3.4 \times 10^{-3} \\
3.77 \times 10^{-6}\end{array}$
\end{tabular}

REFERENCES

1. R. T. Dillon, R. B. Lantz, S. B. Pahwa, "Risk Methodology for Geologic Disposal of Radioactive waste: The Sandia waste Isolation Flow and Transport (SwIFT) Model," SAND-78-1267, October 1978.

2. B. W. Torres and R. J. Balestri, "Consequence Assessment of Radionuclide Release from the WIPP Repository to the Environment, "BDM/TAC-78-497-TR, September 1978. 